Florida International University FIU Digital Commons

3-29-2002

\title{
Compensatory effects of parent and peer support on well-being and achievement during pre-and early adolescence
}

Noel Alexander Crooks

Florida International University

DOI: $10.25148 /$ etd.FI14061544

Follow this and additional works at: https://digitalcommons.fiu.edu/etd

Part of the Psychology Commons

\section{Recommended Citation}

Crooks, Noel Alexander, "Compensatory effects of parent and peer support on well-being and achievement during pre-and early adolescence" (2002). FIU Electronic Theses and Dissertations. 2669.

https://digitalcommons.fiu.edu/etd/2669 


\section{FLORIDA INTERNATIONAL UNIVERSITY}

Miami, Florida

COMPENSATORY EFFECTS OF PARENT AND PEER SUPPORT ON WELLBEING AND ACHIEVEMENT DURING PRE- AND EARLY ADOLESCENCE

A dissertation submitted in partial fulfillment of the requirements for the degree of DOCTOR OF PHILOSOPHY in

PSYCHOLOGY

by

Noel Alexander Crooks 
To: Dean Arthur W. Herriott

College of Arts and Sciences

This dissertation, written by Noel Alexander Crooks, and entitled Compensatory Effects of Parent and Peer Support on Well-being and Achievement During Pre- and Early Adolescence, having been approved in respect to style and intellectual content, is referred to you for judgment.

We have read this dissertation and recommend that it be approved.

William M. Kurtines

Marilyn Montgomery

Nathalie Franco

Mary J. Levitt, Major Professor

Date of Defense: March 29, 2002

The dissertation of Noel Alexander Crooks is approved.

Dean Arthur W. Herriott College of Arts and Sciences

Dean Douglas Wartzok University Graduate School

Florida International University, 2002 


\section{DEDICATION}

I would like to dedicate this body of work to my family, whose love and support made its completion possible. 


\section{ACKNOWLEDGMENTS}

I would like to thank the members of my committee, Dr. William Kurtines, Dr. Marilyn Montgomery and Dr. Nathalie Franco for their assistance, patience and support. Their feedback, availability and understanding made this project a wonderful learning experience.

Special thanks also to the entire Social Networks and Achievement Project (SNAP) team for their support in all phases of this study. Specifically, I would like to thank Dr. Gaston Bustos, Jennifer Hodgetts, Dr. Jennifer Santos, Dr. Avidan Milevsky, Dr. Paige Telan and Dr. Jerry Levitt for the excellent advise, wonderful encouragement and constant reassurance.

Finally, I would like to thank my mentor and major professor, Dr. Mary Levitt for her invaluable guidance and support not only in the completion of this project, but throughout my graduate career. Her love and support has always inspired me to do my very best. 
ABSTRACT OF THE DISSERTATION

COMPENSATORY EFFECTS OF PARENT AND PEER SUPPORT ON WELLBEING AND ACHIEVEMENT DURING PRE- AND EARLY ADOLESCENCE

by

Noel Alexander Crooks

Florida International University, 2002

Miami, Florida

Professor Mary J. Levitt, Major Professor

The current study was designed to explore the salience of parent and peer support in middle childhood and early adolescence across two time periods as indicated by measures of achievement (grade point average (GPA), Stanford Achievement Test (SAT) scores and teacher rated school adaptation) and well-being (loneliness, depression, selfconcept and teacher-rated internalizing behaviors).

Participants were part of an initial study on social network relations and school adaptation in middle childhood and early adolescence. Participants at Time I (in the spring of 1997) included 782 children in grades 4 and 6 of eight lower and middleincome public elementary schools. Participants $(\mathrm{N}=694)$ were reinterviewed two years later in the spring of 1999 (Time 2).

Multivariate analyses of variance (MANOVA) were used to investigate the change in salience of parent and peer support from Time 1 to Time 2. In addition, TukeyHSD (Honestly Significant Difference) post hoc tests were used to test the significance of the differences among the means of four support categories: 1) low parent-low friend, 2) low parent-high friend, 3) high parent-low friend, and 4) high parent-high friend. 
Compensatory effects were observed for loneliness and self-concept at Time 1, as well as for SAT scores, self-concept and overall achievement at Time 2. Results were consistent with existing findings that suggest a competitive model of parent/peer influence on achievement during adolescence. This study affirms the need for a more contextual approach to research examining competing and compensatory effects on adolescent development. 


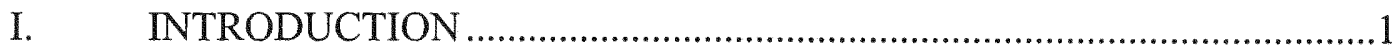

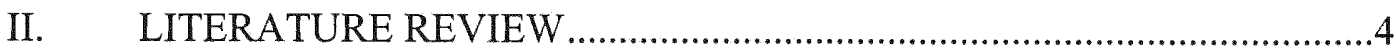

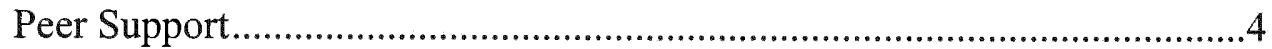

Peer and Parent Support as Complementary and Competing Influences .....10

Peer and Parent Support as Compensatory ..................................................12

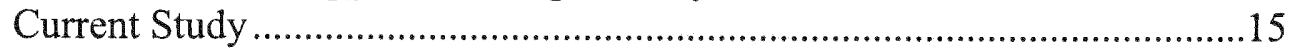

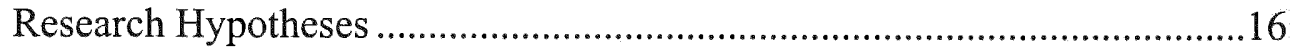

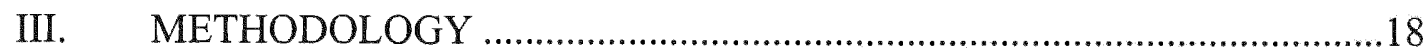

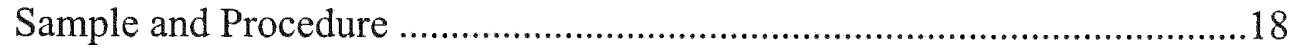

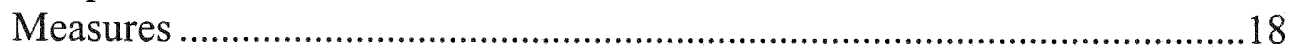

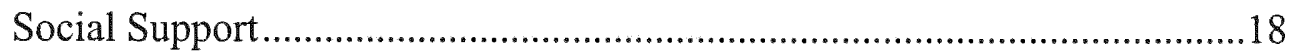

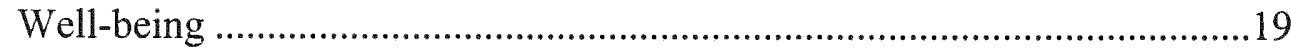

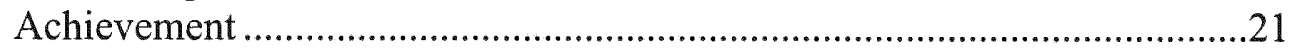

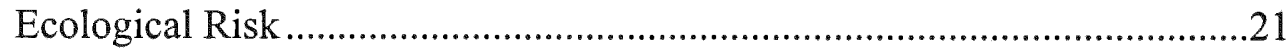

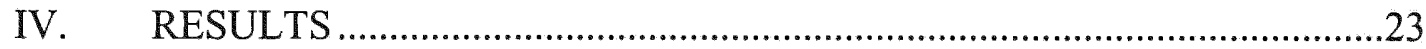

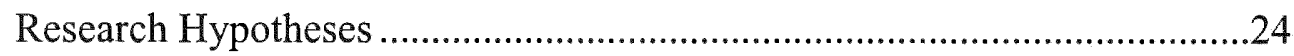

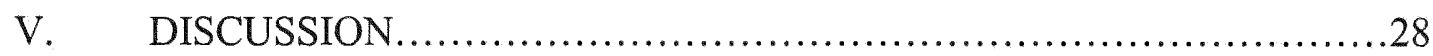

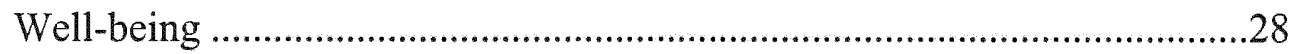

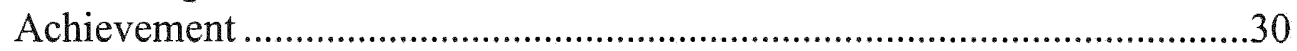

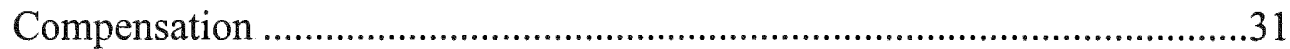

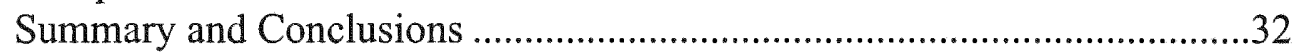

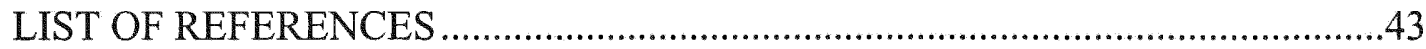

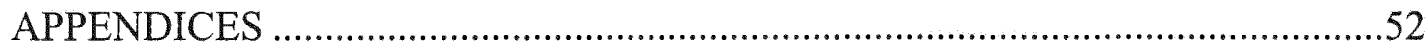

VITA' 


\section{INTRODUCTION}

Thoits (1986) conceptualized social support as a form of assistance that is given to and is received by individuals in their efforts to cope successfully with stressful events. The literature is replete with strong evidence supporting the positive relationship between social support and well-being (Hoffman, Ushpiz \& Levy-Shiff, 1988; Levitt, GuacciFranco \& Levitt, 1994; Komproe, Rijken, Ros, Winnubst \& Hart, 1997; Wenz-Gross, Siperstein, Untch \& Widaman, 1997). Cohen and Wills (1985) found evidence to suggest that this positive correlation may be a result of both a global beneficial (main) effect and a more contextual (buffering) effect that protects the individual from the negative effects of stressful events. Komproe and colleagues (1997) extended the work of Cohen and Wills by examining the mechanisms through which social support may influence wellbeing under stressful circumstances. Results from structural equation modeling indicated that available support had direct beneficial effects on depression, whereas received support had indirect beneficial effects through appraisal and coping.

Like adults, children's subjective appraisal of their social support may be an important mediator of social support effects on well-being. Reid, Landesman, Treder and Jaccard (1989) developed "My Family and Friends," an instrument used to gather information about children's perception of the availability of individuals in their network to provide different types of social support as well as their satisfaction with the help they received. To validate this instrument, 249 children (ages ranging from 6 to 12-years-old) were studied. The results indicate that these subjective impressions about social support in childhood can be reliable and valid. Similar findings indicating high reliability and validity of social support perception were obtained by Levitt, Guacci-Franco and Levitt 
(1993), with a multicultural sample of 333 African-American, Anglo/European-American and Hispanic-American students. Based on the Convoy Model of social support across the life-span (Kahn \& Antonucci, 1980), Levitt and her colleagues used a theoretical and methodological framework that conceptualized the child's social network as a "protective convoy of relationships" providing support to the child. They found that reports of high convoy support were positively correlated with high self-concept and teacher-rated wellbeing measures. These authors also reported links between social support and school achievement (Levitt, Guacci-Franco \& Levitt, 1994). In addition, Franco and Levitt (1997) found that preschool children (ages 4 to 5) had reliable and meaningful perceptions of the structure and function of their social support networks consisting of parents, peers and teachers.

Although there are many sources of support available to the child, sources may vary in their influence on the child's behavior. Furman and Buhrmester (1985) examined such influences by studying children's perceptions of the support obtained from specific members of their social networks: mothers, fathers, siblings, grandparents, friends and teachers. In this study, 199 fifth and sixth-grade children completed Network of Relationships Inventories, which assessed the quality of their relationships with individuals in their social networks. Children reported seeking different types of support from different individuals. For example, mothers and fathers were turned to most often for affection, enhancement of self-worth, reliable aid and instrumental aid. Next to parents, grandparents were turned to most often for affection and self-worth, and teachers were turned to most often for instrumental aid. Friends were the greatest source of companionship and friends and mothers received the highest ratings of intimacy. Conflict 
was perceived as occurring most often in sibling relationships. The children in this sample also felt that their relationships with mothers and fathers were most important.

Due to the apparent salience of their influence on achievement and general wellbeing, the effects of parent and peer support have been the focus of much research. Parent and peer groups have been studied extensively with respect to both quantity and quality of support given to the child. Some may argue that each group contributes distinctive effects on observed outcomes. For example high parent support is often associated with higher GPA, SAT scores and self-esteem (Pettit, Bates \& Dodge, 1997; Hoffman, Ushpiz \& Levy-Shiff, 1988, Mayhew \& Lempers, 1998) whereas high peer support is usually highly correlated with the children's reports of lower loneliness (Asher, Hymel \& Renshaw, 1984). Others have suggested a more cumulative effect of parent and peer support, with each contributing unique variances to achievement and well-being outcomes (Franco \& Levitt, 1998). Such differential effects that highlight the relationship between the type and source of the support received and the types of outcomes observed, have led to several broad themes in parent and peer support research. These themes include: (1) parent and peer support as distinct, non- interacting entities (2) peer support and parent support as complementary effects, (3) parent and peer support as competing influences and (4) peer support and parent support as compensatory (Cooper \& Cooper, 1992). The following review highlights some of the existing research in these four broad categories. 


\section{LITERATURE REVIEW}

Peer Support

Peer interaction is usually viewed as an important and powerful predictor of later well-being. However, positive outcomes are often contingent on the behavior of the peer group from which the support is solicited. As a result, both positive and negative outcomes have been associated with strong peer support in the literature. Conceptions of developmental pathways are sometimes used to link prior difficulties and rejection in peer relationships to later internalizing and externalizing problems (Hymel, Rubin, Rowden \& LeMare, 1990) as well as peer selection and influence (Vernberg, 1990). Suffice to say that these early problems with the peer group may increase the probability of further isolation from the child's "mainstream" cohorts. The data also suggest that these isolated children may then form social clusters consisting of similarly rejected peers who, in turn, may support and reinforce the child's problem behaviors (Hartup, 1996; Dishion, Andrews \& Crosby, 1995; Cairns, Cairns, Neckerman, Gest \& Gariepy, 1988), delinquency (Agnew, 1991; Warr, 1993) and aggression (Hymel et al., 1990). Few studies focused specifically on peer support in relation to these outcomes (Asher \& Dodge, 1986; Urberg, Degirmencioglu, Tolson Halliday-Scher, 1995; Ladd, 1983).

Similarly, studies examining the effects of peer support on achievement have often used methodologies that employed an indirect analysis of the peer support effects. That is, these studies used sociometric status, social competence or peer acceptance as the measure of the peer relationship (DeRosier, Kupersmidt \& Patterson, 1994; Wentzel, 1991; Austin \& Draper, 1984). For example, Wentzel studied the impact of the child's emotional state (depressed or withdrawn) on school achievement after being rejected (or 
accepted) by peers. These types of studies have produced consistent findings relating the popular status and acceptance of the child with successful academic performance and rejected status and low levels of acceptance with academic problems. However little is known about the direct effects of peer support on the child's school achievement (Levitt et al., 1994). Longitudinal studies investigating possible changes in the effects of peer support on school achievement are especially scarce. One such rare find was Wentzel and Caldwell's (1997) longitudinal study examining the relationship of reciprocated friendships, peer acceptance and group membership to academic achievement. In this study, 213 sixth-grade students were followed for two years. Results indicated that the effects of peer relations on academic performance are complex and served many different functions in facilitating high achievement in school. In addition, the researchers found that the effect of peer relationships on GPA over time was indirect, and was heavily influenced by their association with the child's prosocial behavior. Contextual influences, such as environmental risk factors, ethnicity and culture, that moderate the mechanisms responsible for the observed outcomes in achievement are still not well understood.

Attempts at a finer level of analysis concerning the relationship between peer support and achievement have led to important distinctions between peer influence and that of a stable reciprocating friendship. While peer acceptance and interaction focus more on the child's popularity and social standing, friendship relations can be conceptualized as a subset of peer group relations, consisting of more stable, mutual and enduring dyadic-affective bonds (Newcomb \& Bagwell, 1995). Friends have a strong influence on adolescents' adjustment in school (Berndt \& Keefe, 1995), adolescent antisocial behaviors (Dishion, Andrews \& Crosby, 1995), cognitive and social 
scaffolding support (Hartup, 1996), peer group acceptance and lower feelings of loneliness and social dissatisfaction (Parker \& Asher, 1993), and higher delinquency (Vitaro, Tremblay, Kerr, Pagani \& Bukowski, 1997). Berndt and Perry (1986) found that second, fourth, sixth and eighth-graders perceived friends as more supportive than acquaintances. Children's perception of friendships as supportive relationships is an important precursor to the formation and maintenance of the friendship dyad. Parent Support as an Independent Entity

Although there is strong evidence indicating a general positive correlation between high parental involvement and well-being, the data also suggest that parental styles (that is, parental behavior) may have differential effects on achievement. Much research has been generated comparing Baumrind's (1971) typology of the authoritarian, authoritative, and permissive parenting styles in relation to adolescent school performance. There is consistent evidence to indicate that the authoritative parental style is most positively correlated with school achievement (Dornbusch, Ritter, Leiderman, Roberts \& Fraleigh, 1987; Steinberg, Elmen \& Mounts, 1989; Steinberg, Lamborn, Dornbusch \& Darling, 1992). With this style, acceptance, supervision, and psychological autonomy are given and parents are able to modulate their levels of control based on the child's developmental stage. Thus, this "person-environment fit" theory suggests an environment that gradually reduces adult control as the child's desire for appropriate autonomy increases (Eccles, Buchanan, Flanagan, Fuligni, Midgley \& Yee, 1991; Fuligni \& Eccles, 1993; Bogenschneider, Small \& Tsay, 1997).

Some have argued for an integrative model that would study parenting styles from a contextual perspective (e.g., Darling \& Steinberg, 1993). Culture driven attitudes and 
beliefs, as well as risk factors, ethnicity and socioeconomic status often provide the context within which the salience of parental influence is played out (White, 1982;

Stevenson, Chen \& Uttal, 1990; Mickelson, 1990; Steinberg, Dornbusch \& Brown, 1992;

De Haan \& MacDermid, 1998; Leung, Lau \& Lam, 1998; Smith-Maddox, 1999;

Shumow, Vandell \& Posner, 1999). Recent studies examining the complex interaction among supportive parenting styles, ecological context and adjustment have used a longitudinal approach. Pettit, Bates and Dodge (1997) conducted a seven-year longitudinal study to examine: (a) the extent to which early supportive parenting (assessed at prekindergarten) predicted sixth-grade adjustment, after controlling for harsh parenting, and (b) the extent to which supportive parenting buffers the impact of early family adversity on grade six adjustment. Results indicated that supportive parenting predicted adjustment in grade 6 . In addition, a higher level of supportive parenting did moderate the effects of family adversity on later behavior problems. Glasgow, Dornbusch, Troyer, Steinberg and Ritter (1997) found similar predictive relations concerning parental styles, adolescents' attributions, and school outcomes in a two-year longitudinal study with high school participants.

In addition to parenting styles, there has also been some interest in the relationship between parental beliefs (or expectations) and the child's academic achievement. Beliefs that one has the capacity to achieve desired outcomes have been identified as powerful motivational constructs associated with the formation and regulation of personal goals (Wentzel, 1998). Okagaki and Frensch (1998) suggest the importance of considering not just parents' beliefs and goals for their children, but also the type of help parents can realistically offer when trying to facilitate their child's 
achievement. Other studies have emphasized the cultural and ethnic differences surrounding autonomy and conformity in relation to the child's academic development (Okagaki \& Sternberg, 1993; Stevenson, Chen \& Uttal, 1990). Others see parental expectations and beliefs as both a cause and an effect of academic achievement. For example, Seginer (1983) suggests a need for research focused on the antecedents of parents' expectations (for example, feedback from school) and factors mediating between these parental expectations and the child's academic behavior. These mediating factors may include differential reinforcement of behaviors supporting achievement and the child's own aspiration. Parents may use differential reinforcement to increase appropriate behaviors during parental monitoring.

Parents are often concerned about where their children go and with whom they spend time during, as well as after, school. Parental monitoring emphasizes the behavior of parents in their attempts to know their children's whereabouts, companions and activities (Pettit, Bates, Dodge \& Meece, 1999). There is strong evidence of the deleterious effects of high-risk environments on the well-being of the child. Delinquent behavior, substance abuse and poor school adjustment are highly correlated with the unsupervised child living in a high-risk environment (Barnes \& Farrell, 1992; Flannery, Williams \& Vazsonyi, 1999). Coley and Hoffman (1996) examined contextual factors affecting the effects of parenting practices and found that, although children living in dangerous neighborhoods with low supervision and monitoring may experienced positive outcomes with regard to behavior and language skills, they tend to score lower with regards to self-efficacy. In addition, a lack of supervision and monitoring related to low achievement for children in single-parent, but not married-parent households. McLoyd 
(1990), in examining the impact of economic hardship on black families and children, concluded that poverty and economic hardship lower the capacity for supportive, consistent and involved parenting. Thus economic hardship may produce psychological distress, which may, in turn, impact negatively on the parent-child relationship and affect the child's overall adjustment (Lempers, Clark-Lempers, \& Simons, 1989; Conger, Conger, Elder, Lorenz, Simons, \& Whitbeck, 1992; Conger, Conger, Elder, Lorenz, Simons \& Whitbeck, 1993; Brody, Ge, Conger, Gibbons, Murry, Gerrard \& Simons, 2001). Similar findings were obtained by Crouter, Helms-Erikson, Updegraff and McHale (1999), in a study of conditions underlying parents' knowledge about their children's daily lives, for an all white sample of 203 nondivorced, predominantly dualincome families. Results indicated that such knowledge was a function of mother's work involvement, sibling composition, children's temperament and parents' personal qualities (that is, education and attitudes toward gender roles). These results are significant, in that they may help to identify existing obstacles limiting the amount of parental support offered to the child.

Although the effects of parent and peer support are sometimes presented as separate, nonoverlapping entities in the literature, from a social network framework, parent and peer support may jointly contribute to developmental outcomes (Franco \& Levitt, 1998). Thus, as the influence of the peer group increases during adolescence, three patterns of support in relation to that of the primary caregiver are often examined in the literature. These include peer support as complementary, competing, and compensatory to that of parental support. 
Traditional attachment theorists viewed the early parent-child interaction as an important prerequisite in shaping the child's early sense of self (Bowlby, 1969;

Ainsworth, 1973). In this framework, the relationship with the primary caregiver is seen as a template from which a working model for future relationships with friends and peers may develop (Easterbrooks \& Lamb, 1979 \& Lieberman, Doyle \& Markiewicz, 1999). This approach is related to research examining the complementary (or similar) effects of peer and parent support. These studies often highlight the unidirectional influence of parent to child to peer. In this context the parent, having direct influence on the child's behavior may acquire both direct (parental monitoring) and indirect (parental modeling) influences on the child's peer orientation and selection (Lollis, Ross \& Tate, 1992; Ladd, Profilet \& Hart, 1992). As a result of such influence the child may select peers that reflect the values, attitudes and goals of the parent (Bogenschneider, Wu, Raffaelli \& Tsay 1998; Burks \& Parke, 1996).

Some believe that parents influence the child-peer interaction through parallel relationships involving the early modeling of specific skills which include reciprocity, control exchanges, and play (Russell, Pettit, \& Mize, 1998). Others have found that such indirect influences can be maintained through adolescence, with specific parental practices of encouraging academic achievement and joint decision-making (Brown, Mounts, Lamborn \& Steinberg, 1993). Thus, early parent and peer support acting in concert represent a powerful tool in predicting well-being in adolescence (Greenberg, Siegel \& Leitch, 1983; Armsden \& Greenberg, 1987; McFarlane, Bellissimo \& Norman, 1995; Gauze, Bukowski, Aquan-Assee \& Sippola, 1996). 
Pitting parent and peer support against each other is most often seen in the achievement literature, where high parent support is often thought to have a positive effect on the child's school achievement, whereas high peer support is sometimes viewed as a source of distraction in the school environment. With regard to competing effects, some studies have looked at the effects of peers on the behavior of the primary caregiver by examining the contexts in which the influence of peers in high-risk environments elicits protective responses or monitoring behaviors toward the child (Mason, Cauce, Gonzalez \& Hiraga, 1996). Others have investigated how low parental involvement facilitates the adolescent's involvement with problem peers (Dishion, Patterson, Stoolmiller \& Skinner, 1991; Ary, Duncan, Biglan, Metzler, Noell, \& Smolkowski, 1999) and how poor parenting and involvement with deviant peers contribute to adolescent delinquent behavior (Patterson \& Dishion, 1995).

Still others have argued that, although the primary parent-child relationship is important, children, based on their history of interactions, may be capable of drawing specific types of support from different groups within their social support network. The child may identify nonsupportive (that is, nonreinforcing) interactions and, in time, may learn to avoid nonsupportive individuals as well. The child could compensate for a lack of support from one area by seeking out other individuals to provide support functions that were lacking in the earlier relationship. Thus, another approach to the investigation of the parent-child-peer interaction addresses possible compensatory effects from different sources of support. 
East and Rook (1992) discussed two conceptually distinct aspects of compensation. The first involves the behavior of actively seeking alternative social support to make up for deficiencies found in some other relationship. The second, more evaluative aspect of compensation involves the extent to which the compensatory relationship successfully substitutes, as evidenced by a more positive outcome, for the deficient relationship. There have been few studies investigating peer-parent compensatory effects and the findings in this area have been mixed. Patterson, Cohn and Kao (1989) investigated the extent to which maternal warmth serves as a protective factor against risks associated with peer rejection among children. In this study, eighty-one 6year-olds and their mothers participated in a laboratory play interaction the summer before the children entered the first grade. Sociometric assessments were later conducted and the children were classified using social acceptance rating scales. Other assessments included cognitive abilities, self-concept, behavior problems, competence and temperament. Participants who were rejected by their peers and whose interactions with their mothers were low in warmth were rated by teachers as having more behavior problems and were less competent than rejected children reporting high parental warmth. Thus the results suggest that maternal warmth compensated for peer rejection among children.

In a 4-year longitudinal study, Booth, Rubin and Rose-Krasnor (1998) did not find any compensatory effects of best friend support on the social-emotional adaptation of insecurely attached children. Participants were 58 mothers and their 4-year-old children who participated in a mother-child-peer interaction session. These children then 
returned to the lab for a peer-play session at age 8 . Preschool attachment security predicted age 8 perceptions of maternal support better than the actual behaviors of mothers at age 8 . The child's ability to identify a best friend as a member of the child's emotional support network was related positively to social competence but not to security. The data suggest that among insecurely attached children, the greater the reliance on the best friend for emotional support, the greater the externalizing problems.

Van Aken and Asendorpf (1997) investigated compensation across relationships with 139 12-year-old participants using correlations of support and well-being (selfesteem). Children in this Munich sample were interviewed about their network relationships. The results indicated that level of social support was somewhat specific to particular types of network members. In addition, low support from the immediate family was fairly independent of low support from other relationships. Low support from one parent could only be compensated for by support from the other parent and low support by classmates was not compensated for by support from other children. Support was strongly associated with low self-worth for the relationships with the mother and father and self-worth was also associated, but to a lesser extent, with the relationships with classmates. The extent to which parents compensated for low friend support was not reported in this study.

Stocker (1994) found evidence for a compensatory model while investigating children's perceptions of relationships with siblings, friends and mothers. Eighty-five Caucasian second graders (average age 7 years 11 months) participated in this study. Measures were taken on friendships, sibling relationships, maternal warmth, loneliness, depressive mood, self-worth, and behavioral conduct. The results indicated that children 
who reported warm relationships with either their close friends or their mothers (or both) did not differ from each other and had better outcomes than children who reported low levels of warmth with both mothers and friends. Stocker concludes that children with the poorest adjustment scores may lack the skills to develop warm relationships with either friends or mothers.

Some studies have found little evidence of a compensatory model. These include East and Rook's (1992) study investigating whether or not siblings and non-school friends can compensate for low peer support in school and van Beest and Baerveldt's (1999) study of Dutch adolescents investigating the extent to which low parental support will be compensated with support from peers. However, in these studies, ethnic and cultural differences may create contextual determinates that could mediate the salience of compensatory effects. In a longitudinal study involving 267 Canadian adolescents, Brendgen, Vitaro and Bukowski (1998) found a mediated relationship in which a perceived lack of closeness with parents was related to early adolescents' association with delinquent friends. However, this compensatory relationship was seen only in adolescents who were either attracted to delinquent friends because of the similarity to their own behavior or rejected by the majority of their peers. Drawing from a traditional developmental perspective, one could hypothesize that the salience of parent and peer effects, (including compensatory influences) might be highly correlated with the child's stage of development (Berndt, 1979; Chassin, Presson, Sherman, Montello \& McGrew, 1986). Thus parental support in middle childhood may be more critical to both the achievement and well-being of the child, whereas increased peer support may contribute a more salient compensatory effect for low parental support during adolescence. 


\section{Current Study}

To date, existing compensatory studies have not addressed the extent to which the salience of support provided by parents and peers may change over time.

Longitudinal studies capable of tracking these shifts in compensatory effects along the developmental continuum could provide an ecological approach that would take us one step closer to identifying and understanding the proximal variables responsible for diverse but equally interesting outcomes. These studies could afford us a richer, more meaningful analysis of the contextual influences of the social support network on the child's behavior.

Thus, the current longitudinal analysis was designed to explore the salience of parent and peer support in middle childhood and early adolescence. Specifically, this study investigated potential differences in compensatory effects of parent and peer support across two time periods, as indicated by measures of achievement and wellbeing. In addition, the role of contextual determinants, such as age (as indicated by grade effects), as well as possible influences of high versus low risk environments were also examined.

The data were drawn from a larger study of social networks, well-being, and achievement in the transition to middle school. Interview and achievement data were collected initially when participants were in grades 4 and 6 and again two years later. It was predicted that parental influence would be more salient in middle childhood (or preadolescence) with fewer compensatory effects of peer support observed at Time I. It was further predicted that, at Time 2 (early adolescence), the compensatory influence of friends would be more salient than at Time I. Five specific hypotheses 
were proposed. The first three hypotheses addressed emotional well-being; the latter two were concerned with achievement.

\section{Hypothesis 1:}

At both Time 1 and Time 2, across grade levels, children with high support from parents and friends and those with high support from either parents or friends will have better outcomes on emotional well-being measures (self, loneliness, depression, and teacherrated internalizing behavior) than those with low parent and low friend support.

\section{Hypothesis 2:}

At Time 1, based on greater salience of parent support to emotional well-being during preadolescence in the literature, children with high parent and low friend support will have better outcomes than those with low parent, high friend support, especially for the younger (4th grade) children.

\section{Hypothesis 3:}

At Time 2, children with high friend support and low parent support will do as well as those with high parent and low friend support, and both groups will do better than those with low parent and low friend support, especially for the older (8th grade) group, given the increased salience of peer support during adolescence. In other words, friend support is more likely to compensate for low parent support in adolescence, with respect to emotional well-being outcomes.

\section{Hypothesis 4:}

At Time1 and Time 2, participants with high parent support will have better academic outcomes (GPA, SAT scores, and teacher-rated school adaptation) than those with low parent support. High friend support may also contribute to better achievement in high 
risk conditions at younger ages, as peers may be more supportive of achievement at a younger age.

\section{Hypothesis 5:}

At Time 2, adolescents with low parent and high friend support will have worse academic outcomes than those with high parent, high friend or high parent, low friend support. In high risk conditions, those with high parent, low friend support will do better than those with high parent, high friend support because, under high risk conditions, friend support may compete with parent support with respect to academic outcomes. These effects will be most pronounced for older (8th grade) adolescents. 


\section{METHODOLOGY}

\section{Sample and Procedure}

The sample for this study took part in a larger study on social network relations and school adaptation in middle childhood and early adolescence. Participants at Time I (in the spring of 1997) included 782 children in grades 4 (mean age 9.7 years) and 6 (mean age 11.7 years) of eight lower and middle income public elementary schools in Miami-Dade County, Florida. Participants $(\mathrm{N}=694)$ were reinterviewed two years later in the spring of 1999 (Time 2). The present study was based on data for participants interviewed at Time 1 and Time 2 . Of these students, 356 were female and 338 were male. The sample was ethnically and economically diverse and included 220 AfricanAmerican, 193 European-American and 281 Hispanic-American students.

Informed consent was obtained from parents for all child participants of the original sample. After consent was given, interviews were conducted individually with each student by one female interviewer matched to the child according to ethnicity. The interviews were conducted within the school setting in a private area.

\section{$\underline{\text { Measures }}$}

Measures include indices of social support from parents and friends, in addition to measures of ecological risk and adjustment. Adjustment measures include self-concept, loneliness, depression, teacher-rated internalizing behaviors and school adaptation, grades, and achievement test scores. The following specific measures were analyzed in the study.

Social Support. [APPENDIX A] Parent and friend support were assessed using the Children's Convoy Mapping Procedure (Levitt et al., 1993). With this procedure 
children identified the people in their life who are close and important to them in a concentric circle map, with the closest and most important persons in the inner circle. The participants then indicated which persons provided specific support functions.

Specifically, they were asked to identify the people "you talk to about things that are really important to you," "who make you feel better when something bothers you or you are not sure about something," "who would take care of you if you were sick," "who help you with homework or other work you do for school,' " who like to be with you and do fun things with you," and "who make you feel special or good about yourself." Scales of parent and friend support were obtained by summing the number of support functions provided within each of these two relationship categories. The alpha reliability for the sample was .83.

Adjustment Measures. Adjustment measures include the Harter (1985) SelfPerception Profile, the Children's Loneliness Scale (Asher, Hymel \& Renshaw, 1984), the Child Behavior Checklist - Teacher Version (Edelbrock \& Achenbach, 1984), school grades, and Stanford Achievement Test scores. These measures represented a combination of self-rated as well as observed indices of well-being and achievement. Measures of Well-being

Self-concept. [APPENDIX A] The social, cognitive and general self-concept subscales of the Harter Self-Perception Profile (1985) were used to assess self-concept. A sample item is, "Some kids are often unhappy with themselves BUT other kids are pretty pleased with themselves." Participants first decide which description is true of themselves and then indicate whether the choice is "sort of true for me" or "really true for me." Each 
item is given a score from 1 to 4 , with higher scores indicating a more positive selfconcept. The alpha reliability for the sample was .83 .

Loneliness. [APPENDIX A] The Children's Loneliness Scale, an abbreviated version of the 16-item loneliness scale developed by Asher, Hymel \& Renshaw (1984), used to measure loneliness. The scale, measuring loneliness and social dissatisfaction, has been found to have high internal consistency and reliability. Sample items include "I feel alone at school" "I can find a friend in my class when I need one" and "I feel left out of things I my school." Responses range from 1 "not at all true about me" to 5 "always true about me." A score of 5 indicates higher levels of loneliness. The alpha reliability for the sample was .67 .

Depression. [APPENDIX A] The short form of the Children's Depression Inventory (CDI-S) was used as a self-report on depressive symptoms in children (Kovacs, 1992). The short version was chosen due to its utility for nonclinical populations. It is a ten-item scale that has been widely used with children and adolescents and has good internal and test-retest reliabilities. Sample items include "I am sad many times," "Nothing will work out for me," and "I look OK." Children are asked to choose one statement from a group of three that best describes their feelings within the past two weeks. Scores range from 0 through 20 , with higher scores indicating a greater feeling of depression. The alpha reliability for the sample was .74.

Internalizing Behaviors. [APPENDIX A] The Child Behavior Checklist (CBCL) Teacher Report Form, (Achenbach \& Edelbrock, 1991), a 112 item checklist, was be used to measure internalizing problem behaviors. The internalizing component consists of anxious-depressive behaviors, social withdrawal, and somaticization. One example of 
an internalizing sample items is "Too fearful or anxious." For each item, the teacher indicates the extent to which the item describes the child, 0 "not true," 1 "somewhat or sometimes true," or 2 "very true or often true." Items are summed to create the internalizing and externalizing subscales. Only the internalizing scales were used in this study. The alpha reliability for the sample was .77 .

Measures of Achievement

School Adaptation. [APPENDIX A] A 14-item School Adaptation Scale developed by Alexander, Entwistle, and Dauber (1993) was used to assess the child's behavior as rated by teachers on a Likert format scale. Examples of items include (a) very enthusiastic, interested in a lot of different things (b) rather high-strung (c) fights too much (d) is creative or imaginative and (e) is disobedient at school. The alpha reliability for the sample was .87 .

Classroom grades and Stanford Achievement Test scores were obtained for each participant from centralized school records. The means of reading, math computation, and math application subtest scores were calculated to create an overall Stanford tests score for each participant. Grade point averages were calculated as the mean of the participant's end of year grades for language arts (Reading, English) and mathematics courses.

Measures of Ecological Risk.

A cumulative risk index was created from six risk factors described below. Scores range from 0-7 with higher scores indicating greater levels of risk. One point was assigned for five of the risk factors and up to 2 points were assigned for the risk factor 
that assessed whether one or both parents were living at home. The six risk factors include the following. The median score of ecological risk for the sample was 2.0 .

School Economic Level. School economic level is based on whether more than $85 \%$ of the student body was eligible for the federally funded free lunch program. Those students in low school economic levels were assigned one point.

Free lunch status. One point was assigned if the student was eligible for free lunches.

Stressful Life Events. [APPENDIX A] Those students who scored above the median on a stressful life events scale (Holmes \& Raye, 1980; Johnson, 1986) received a point. The median score of the stressful life events for the sample was 5.0.

Parent not in Home. One point was given to students when one parent was missing from the home. Two points were assigned to students with both parents missing from the home.

Economic Stress. A point was assigned to those students who scored above the median on a question that assessed how often their parents, "have problems paying for things the family really needs, like food, clothing and rent." The median score of economic stress for the sample was 3.0.

Neighborhood Satisfaction. [APPENDIX A] A point was assigned to those students who scored below the median on a neighborhood satisfaction scale. The median score of neighborhood satisfaction for the sample was 2.30 . 


\section{RESULTS}

Four support-pattern groups were created using a median split of parent and peer support at Time 1. The four support groups were as follows: 1) High Parent High Friend, 2) High Parent Low Friend, 3) Low Parent High Friend and 4) Low Parent Low Friend. This study assesses the predictive utility of these support patterns as they relate to outcome measures of well-being and achievement across time.

Z-score transformations were conducted on individual emotional well-being and school achievement indices and these were then combined to form overall well-being and achievement dependent measures. Multivariate analyses of variance (MANOVA) of wellbeing and achievement were used to investigate the effects of parent and peer support patterns from Time 1 to Time 2, with three between-factors and one within-factor. The three between-factors were support pattern, grade and risk. The within-factor was Time (Time 1 and Time 2). When the overall combined scores were significant, follow-up analyses of the individual well-being and achievement measures were conducted and Tukey-HSD post hoc tests were then used to test the significance of the differences among the means of the four support patterns.

There were significant main effects of support pattern for both well-being and achievement and univariate main effects were significant for all of the specific variables as well, although the effects were marginal for depression at Time 2. Means, standard deviations, and effects for each of the well-being and achievement measures are presented in Tables 1 and 2. The patterns of effects for the aggregate well-being and achievement indices are depicted in Figures 1 and 2. The following results were obtained. 
Hypothesis 1: At both Time 1 and Time 2, across grade levels, children with high support from parents and friends and those with high support from either parents or friends will have better outcomes on emotional well-being measures (self, loneliness, and teacher-rated withdrawal, anxiety and depression) than those with low parent and low friend support.

At Time 1, for self-concept and loneliness outcome measures only, children reporting high parent/high friend support (support pattern 4), high parent/low friend support (support pattern 3) and low parent/high friend (support pattern 2) scored significantly higher than children reporting low parent/low friend support (support pattern 1). These effects were not observed at Time 2, as support patterns 1 and 2 were not significantly different across the well-being measures.

Hypothesis 2: At Time 1, based on greater salience of parent support to emotional wellbeing during preadolescence in the literature, children with high parent and low friend support will have better outcomes than those with low parent, high friend support, especially for the younger (4th grade) children.

At Time 1, for the self-concept measure only, support pattern 3 (high parent/low friend) was significantly greater than support pattern 2 (low parent/high friend). Support effects did not differ by grade level.

Hypothesis 3: At Time 2, children with low parent support and high friend support will do as well as those with high parent and low friend support, and both groups will do better than those with low parent and low friend support, especially for the older (8th grade) group, given the increased salience of peer support during adolescence. In other 
words, friend support is more likely to compensate for low parent support in adolescence, with respect to emotional well-being outcomes.

There were no significant differences between support pattern 1 (low parent/low friend) and support pattern 2 (low parent/ high friend) on any of the well-being indices at Time 2. Support effects did not differ by grade level.

Hypothesis 4: At Time1 and Time 2, participants with high parent support will have better academic outcomes (GPA, SAT scores, and teacher-rated school adaptation) than those with low parent support. High friend support may also contribute to better achievement in high risk conditions at younger ages, as peers may be more supportive of achievement at a younger age.

At Time 1, with regards to support pattern 4 , children having high parent/high friend support had achievement outcomes that were significantly better than support patterns 1 (low parent/low friend) and 2 (low parent/high friend) on all achievement measures. In addition, support pattern 3, (high parent/low friend) had significantly better outcomes than support pattern 1 with regards to overall achievement, GPA and SAT scores. However, support pattern 3 was not significantly different from support pattern 2 on any of the achievement measures at Time 1.

At Time 2, except for school adaptation, support pattern 4 had achievement outcomes that were significantly better than support patterns 1 and 2 . With regards to support pattern 3, the means were significantly higher than support pattern 1 for overall achievement, GPA and SAT scores and significantly higher than support pattern 2 for overall achievement, and school adaptation. 
There were no differences in support effects by grade at Times 1 and 2 for overall achievement and there was a near significant interaction of support pattern by risk by time for the overall achievement measure, $\underline{F}(3,672)=2.46, \underline{p}=.06$. Support pattern effects by risk at Times 1 and 2 are presented in Table 3 and depicted in Figures 3 and 4 . At low risk, achievement was significantly higher for support pattern 4 (high parent/high friend) than for support pattern 1 (low parent/low friend) at Time 1. For low risk at Time 2, there were no significant differences between the four support groups. However at Time 1, for overall achievement at high risk, children in support pattern 4 (high parent/high friend) had a mean that was significantly higher than support patterns 1,2 and 3 . In addition, at high risk at Time 2, support pattern 4 had a mean that was significantly higher than support patterns 1 and 2. However, support pattern 4 was not significantly different from support pattern 3 (high parent/low friend) and support pattern 3 in turn, was not significantly different from support patterns 1 and 2.

Hypothesis 5: At Time 2, adolescents with low parent and high friend support will have worse academic outcomes than those with high parent/high friend or high parent/low friend support. In high risk conditions, those with high parent, low friend support will do better than those with high parent, high friend support because, under high risk conditions, friend support may compete with parent support with respect to academic outcomes. These effects will be most pronounced for older (8th grade) adolescents.

At Time 2, children in support pattern 3 (high parent/low friend) had means that were significantly larger than support pattern 2 (low parent/high friend) for overall achievement and school adaptation. While not significant, this group (support pattern 3) 
also boasted a mean that was larger than children in support pattern 4 (high parent/high friend). Support pattern 4 (high parent/high friend) had means that were significantly larger than children in support pattern 2 in overall achievement, GPA and SAT scores. As indicated above, there were no significant grade effects and no significant differences between the four support patterns at low risk. At high risk, children in support pattern 4 (high parent/high friend) reported a mean that was not significantly different from support pattern 3, but was significantly different from support patterns 1 and 2 . Support pattern 3 in turn, was not significantly different from support patterns 1 and 2 . 


\section{DISCUSSION}

As indicated in the literature, the influence of parents and peers on the child's behavior is usually multidimensional, and often requires the additional analysis of contextual determinants (developmental level, risk factors, etc.). Thus, the differential effects of support from parents and peers (as illustrated by diverse outcomes) are sometimes related not only to the amount of support received from parents and peers (high versus low support), but to specific times at which the support is given and under what conditions (e.g., high versus low risk) along the developmental continuum. The purpose of this study was to explore the possible changes in the salience of parent and peer support during pre- and early adolescence, by comparing the differences in wellbeing and achievement outcomes as they relate to four distinct support patterns.

\section{Well-being}

Results addressing the first and third hypotheses in this study were intriguing in that, with the exception of self-concept and loneliness at Time 1, there were no significant differences observed between support pattern 1 (low parent/low friend) and support pattern 2 (low parent/high friend). Particularly interesting was the apparent beneficial effects of peer support with regards to self-concept and loneliness observed at Time 1, but not at Time 2 (see hypothesis 3 ). These results were counter indicative for two reasons. First, research indicates that parental support can be especially salient during the child's early development and that such low support from parents may have deleterious effects on early self-concept and to a lesser extent, loneliness. This was not observed at the younger (Time 1) developmental level. Second, the more salient effect of high friend support predicted at Time 2 was not substantiated by these results. Thus the 
high friend support reported by children in support pattern 2 did not significantly improve their outcome in terms of well-being. In sum, high friend support did not compensate for low parent support in adolescence with respect to emotional well-being outcomes.

With regards to the second hypothesis, with the exception of self-concept, there were no significant differences between support pattern 2 (low parent/high friend) and support pattern 3 (high parent/low friend) at Time 1. However these findings do suggest that, although children with low parent/high friend support at Time 1 did not differ significantly from those reporting low parent/low friend support at Time 1, children who reported high parent/low friend support at Time 1 had, for the most part, well-being measures that were significantly greater than those reporting low parent/low friend support.

As was expected (with the exception of depression at Time 2) support pattern 4 (high parent/high friend) had outcomes that were significantly better than support pattern 1 on all well-being measures for both Time 1 and Time 2 . However, of particular interest was the finding that support pattern 4 , with regards to depression, was not significantly different from support patterns 1 and 2. One possible explanation for this intriguing finding may be that high support from both parents and peers, if competing in its effect, may result in higher reports of depression than would have been expected from this group (McFarlane, Bellissimo \& Norman, 1995). In general, however, the results suggest that parental support continues to play an important role in children's emotional well-being across the transition to adolescence. 


\section{Achievement}

Results relating to hypothesis four are consistent with the existing literature in suggesting a strong association between high parental support and achievement in that with the exception of SAT scores at Time 2 , there was no indication that participants with support pattern 2 (low parent/high friend) had means that were significantly different from those with support pattern 1 (low parent/low friend) across the achievement measures, even at younger ages.

In the case of overall achievement, at Time 1, low risk participants with support pattern 4 (high parent/high friend) were significantly higher than those with support pattern 1(low parent/low friend). However, such dual support for achievement (as seen in pattern 4) was not significantly greater in effect than the high support of friends in support pattern 2 or the high support of parents in support pattern 3 . Thus, for preadolescents, under low risk conditions, support appears to facilitate achievement regardless of the source.

At Time 2, at low risk, there were no significant differences among the means of all four support categories for overall achievement. With regards to high parent/high friend support at Time 2, friends may be less supportive of achievement, thus presenting a competing model, which at low risk, could diminish any differences among parent/peer support patterns.

Support effects were more differentiated under high risk conditions. At Time 1, at high risk, support pattern 4 (high parent/high friend) was significantly more positive than support patterns 1, 2 and 3 for overall achievement. This may be due in part to the greater salience of high parent support in combination with high friend support, if friends are still 
supportive of achievement at Time 1. Although high parent support continued to be salient during high risk at Time 2, adolescent friends may be less supportive of achievement and this could compete with high parent support. Thus, at Time 2, support pattern 4 had an overall achievement mean that was significantly greater than support patterns 1 and 2, but not significantly different from support pattern 3 (high parent/low friend).

With regards to hypothesis five, the results indicate better achievement outcomes for support patterns 3 and 4 at Time 2. These findings may support the competing model of the parent-peer relationship, in that the high friend support element of support pattern 2 does not support achievement in school. Interestingly, this competing model may also hold true for support pattern 4 (high parent/high friend) in the area of school adaptation. In this subcategory of school achievement, support pattern 4 was not significantly different from support patterns land 2. Thus, as in the results for depression, children in support pattern 4 may receive conflicting support from parents and peer that may interfere with their school adaptation. In comparing the findings concerning well-being and achievement, it would appear that, for the most part, there were more significant differences between support categories 2 and 3 for achievement at Time 2 than for wellbeing at Time 2 . This suggests that a competing model is more descriptive of parent/peer influence on achievement during adolescence.

\section{Compensation}

Compensation involves the extent to which one relationship successfully substitutes, as evidenced by a more positive outcome, for a deficient relationship (East \& Rook, 1992). Drawing from the literature's theoretical conceptualization of 
compensation, where low support from one group can be compensated with high support from another, two compensatory support patterns were identified in this study.

The first pattern was seen in the loneliness outcome measure at Time land the SAT outcome measure at Time 2. In both scenarios, children in support patterns 2 and 3 had means that were significantly different from those of support pattern 1 (low parent/low friend), but not significantly different from each other, and, in the case of loneliness, not significantly different from the mean of support pattern 4 (high parent/high friend). Thus it would appear that low parent/high friend and high parent/low friend may have had outcomes that were similar because friends in support pattern 2 successfully compensated for low parent support with regards to SAT at Time 2, while parents in support pattern 3 successfully compensated for low friend support with regards to loneliness at Time 1.

The second form of compensation involves support patterns 3 and 4 in the areas of self-concept at both Time 1 and Time 2, and overall achievement at Time 2 . In these cases, children within support pattern 3 (high parent/low friend support) had means that were significantly higher than support patterns 1 and 2 (low parent/low friend and low parent/high friend) and not significantly different from support pattern 4 (high parent/high friend). In these examples, it would appear that parents in support pattern 3 successfully compensated for low friend support and, in doing so, facilitated outcomes that were similar to support pattern 4 .

\section{Summary and Conclusions}

A few limitations were identified in this study. First, this study did not focus on the movement of individuals in or out of a support category but rather 
highlighted the predictive properties with regards to outcomes, of the support patterns from Time 1 to Time 2 . Second, small cell sizes prevented the secondary analysis of the outcome means of the extreme (high versus low) support groups.

In spite of these limitations, this study does affirm the need for a more contextual approach to research examining competing and concurrent effects on adolescent development (Gonzalez, Cauce, Friedman \& Mason, 1996). Thus, while some studies indicate that parents and peers contribute distinct and unique variances to observed outcomes, this study further contributes to the existing literature by examining patterns of parent and peer support that reveal both compensatory and competing functions (or roles) of parents and peers that may vary according to environmental conditions or circumstances. 
TABLES 
Table 1. Support Pattern and Well-Being at Times 1 and 2

\begin{tabular}{|c|c|c|c|c|c|c|}
\hline & 1.LoP-LoF & 2.LoP-HiF & 3.HiP-LoF & 4.HiP-HiF & & \\
\hline Time 1 & Mean (SD) & Mean (SD) & Mean (SD) & Mean (SD) & $\underline{F}$ & Effects $^{\mathrm{a}}$ \\
\hline Well-Being & $-.22(.68)$ & $-.06(.62)$ & $.11(.58)$ & $.15(.55)$ & $13.68 * * *$ & $\begin{array}{l}1<3,4 \\
2<4\end{array}$ \\
\hline $\begin{array}{l}\text { Self- } \\
\text { Concept }\end{array}$ & $2.88(.50)$ & $3.01(.51)$ & $3.17(.47)$ & $3.28(.44)$ & $23.04 * * *$ & $1<2<3,4$ \\
\hline Loneliness & $2.12(.74)$ & $1.85(.66)$ & $1.80(.66)$ & $1.67(.66)$ & $13.85^{* * *}$ & $2,3,4<1$ \\
\hline Depression & $1.28(.31)$ & $1.22(.27)$ & $1.15(.23)$ & $1.16(.21)$ & $9.01 * * *$ & $3,4<1$ \\
\hline Internal & $7.39(8.53)$ & $5.74(6.36)$ & $5.77(7.16)$ & $4.44(5.49)$ & $5.24 * *$ & $4<1$ \\
\hline \multicolumn{7}{|l|}{ Time 2} \\
\hline Well-Being & $-.13(.65)$ & $-.01 \quad(.67)$ & $.08(.59)$ & $.63(.59)$ & $4.10^{* *}$ & $1<3,4$ \\
\hline $\begin{array}{l}\text { Self- } \\
\text { Concept }\end{array}$ & $3.02(.50)$ & $3.10(.51)$ & $3.25(.46)$ & $3.27(.44)$ & $11.28 * * *$ & $1,2<3,4$ \\
\hline Loneliness & $1.94(.73)$ & $1.80(.68)$ & $1.73(.69)$ & $1.67(.58)$ & $5.36^{* * *}$ & $3,4<1$ \\
\hline Depression & $1.20(.27)$ & $1.18(.23)$ & $1.14(.20)$ & $1.16(.22)$ & $2.49+$ & $3<1$ \\
\hline Internal & $5.53(6.79)$ & $5.46(7.36)$ & $4.08(6.20)$ & $3.39(4.88)$ & $4.96 * *$ & $4<1,2$ \\
\hline
\end{tabular}

${ }^{\mathrm{a}}$ Indicates means that were significantly different in Tukey HSD post hoc comparisons at $p<.05$.

$* * * \mathrm{p}<.001{ }^{* *} \mathrm{p}<.01 .{ }^{*} \mathrm{p}<.05$. 
Table 2. Support Pattern and Achievement at Times 1 and 2

\begin{tabular}{|c|c|c|c|c|c|c|}
\hline & 1.LoP-LoF & 2.LoP-HiF & 3.HiP-LoF & 4.HiP-HiF & & \\
\hline Time 1 & Mean (SD) & Mean (SD) & Mean (SD) & Mean (SD) & $\underline{F}$ & Effects $^{\mathrm{a}}$ \\
\hline Achieve & $-.28(.79)$ & $-.14(.79)$ & $.05(.82)$ & $.36(.79)$ & $20.99 * * *$ & $\begin{array}{l}1<3,4 \\
2,3<4\end{array}$ \\
\hline GPA & $2.18(.82)$ & $2.31(.80)$ & $2.47(.81)$ & $2.75(.80)$ & $16.10^{* * *}$ & $1<3<4$ \\
\hline SAT & $637.96(45.60)$ & $647.71(47.45)$ & $659.74(49.23)$ & $677.49(45.39)$ & $23.12 * * *$ & $\begin{array}{l}1<3<4 \\
2<4\end{array}$ \\
\hline $\begin{array}{l}\text { School } \\
\text { Adap. }\end{array}$ & $4.48(.94)$ & $4.51(.94)$ & $4.66(.94)$ & $4.89(.96)$ & $7.13^{* * * *}$ & $1,2<4$ \\
\hline Time 2 & & & & & & \\
\hline Achieve & $-.24(.76)$ & $-.15(.82)$ & $.08(.74)$ & $.29(.74)$ & $17.02 * * *$ & $1,2<3,4$ \\
\hline GPA & $1.96(.99)$ & $1.97(1.03)$ & $2.23(.92)$ & $2.43(.92)$ & $9.30 * * *$ & $\begin{array}{l}1,2<4 \\
1<3\end{array}$ \\
\hline $\mathrm{SAT}$ & $645.01(36.36)$ & $657.5(38.06)$ & $663.78(38.76)$ & $684.80(36.38)$ & $31.42 * * *$ & $1<2,3<4$ \\
\hline $\begin{array}{l}\text { School } \\
\text { Adap. }\end{array}$ & $4.67(.79)$ & $4.62(.95)$ & $4.88(.81)$ & $4.78(.86)$ & $3.03^{*}$ & $2<3$ \\
\hline
\end{tabular}

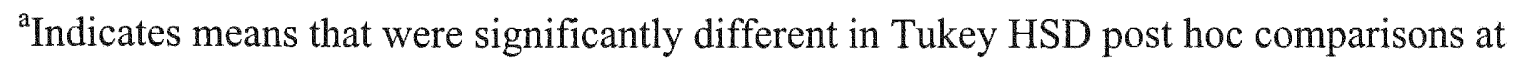
$p<.05$.

$* * * \mathrm{p}<.001 . * * \mathrm{p}<.01 .{ }^{*} \mathrm{p}<.05$. 
Table 3. Support Pattern and Overall Achievement at Times 1 and 2 by Risk

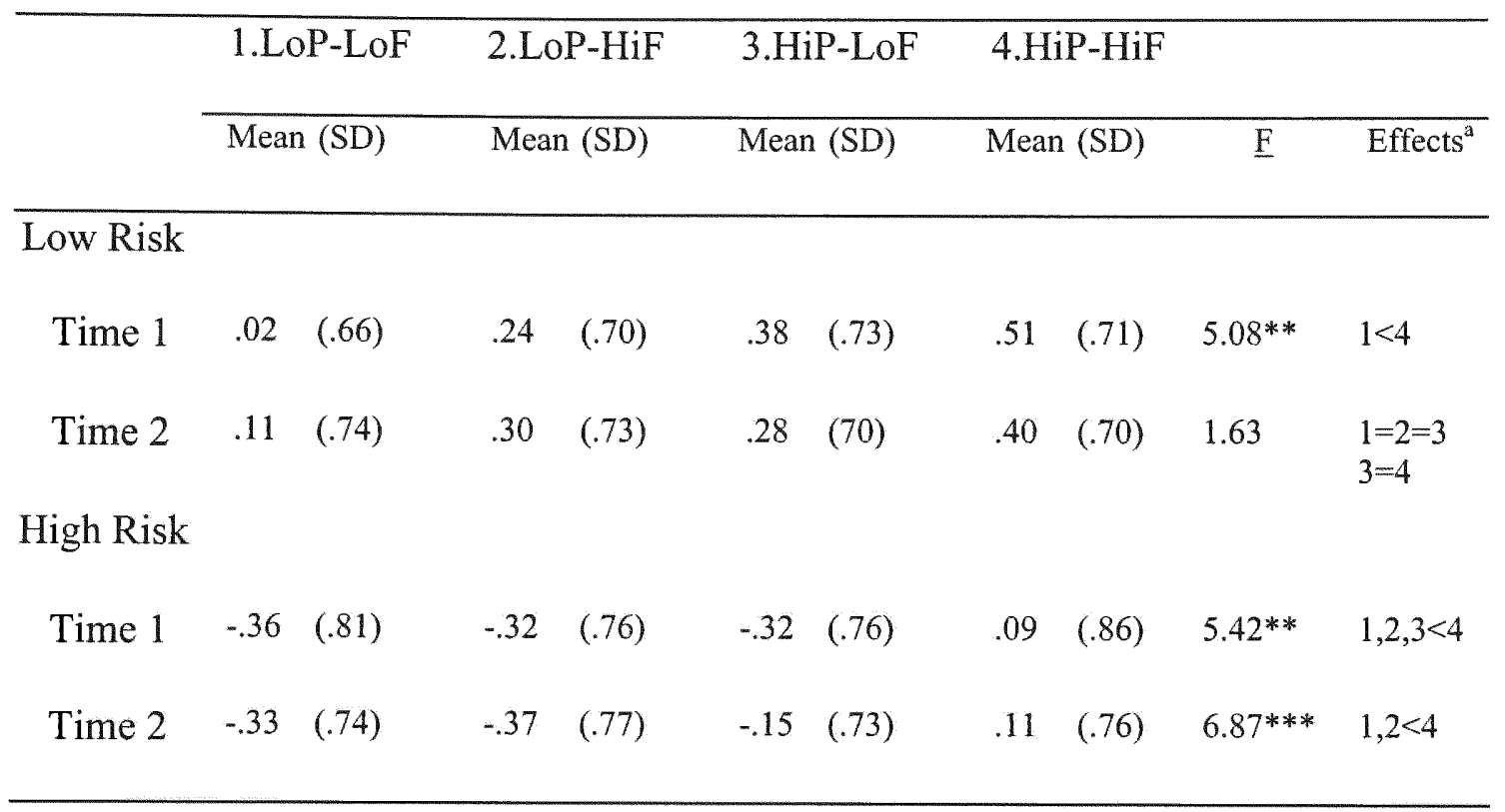

${ }^{a}$ Indicates means that were significantly different in Tukey HSD post hoc comparisons at $p<.05$.

${ }^{* * *} \mathrm{p}<.001 .{ }^{* *} \mathrm{p}<.01 .{ }^{*} \mathrm{p}<.05$ 
FIGURES 
Figure 1.

\section{Well-Being by Support Pattern}

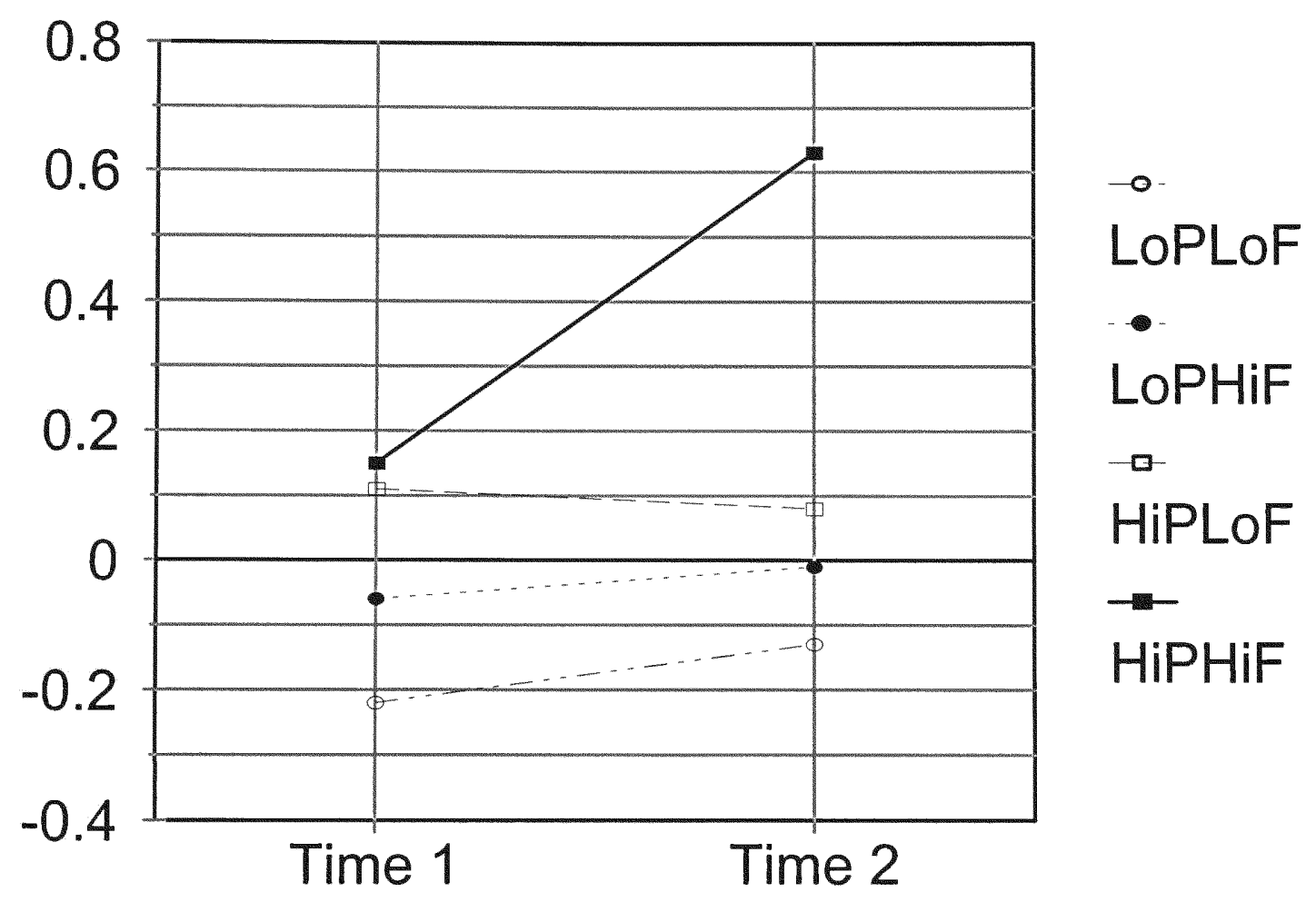


Figure 2.

\section{Achievement by Support Pattern}

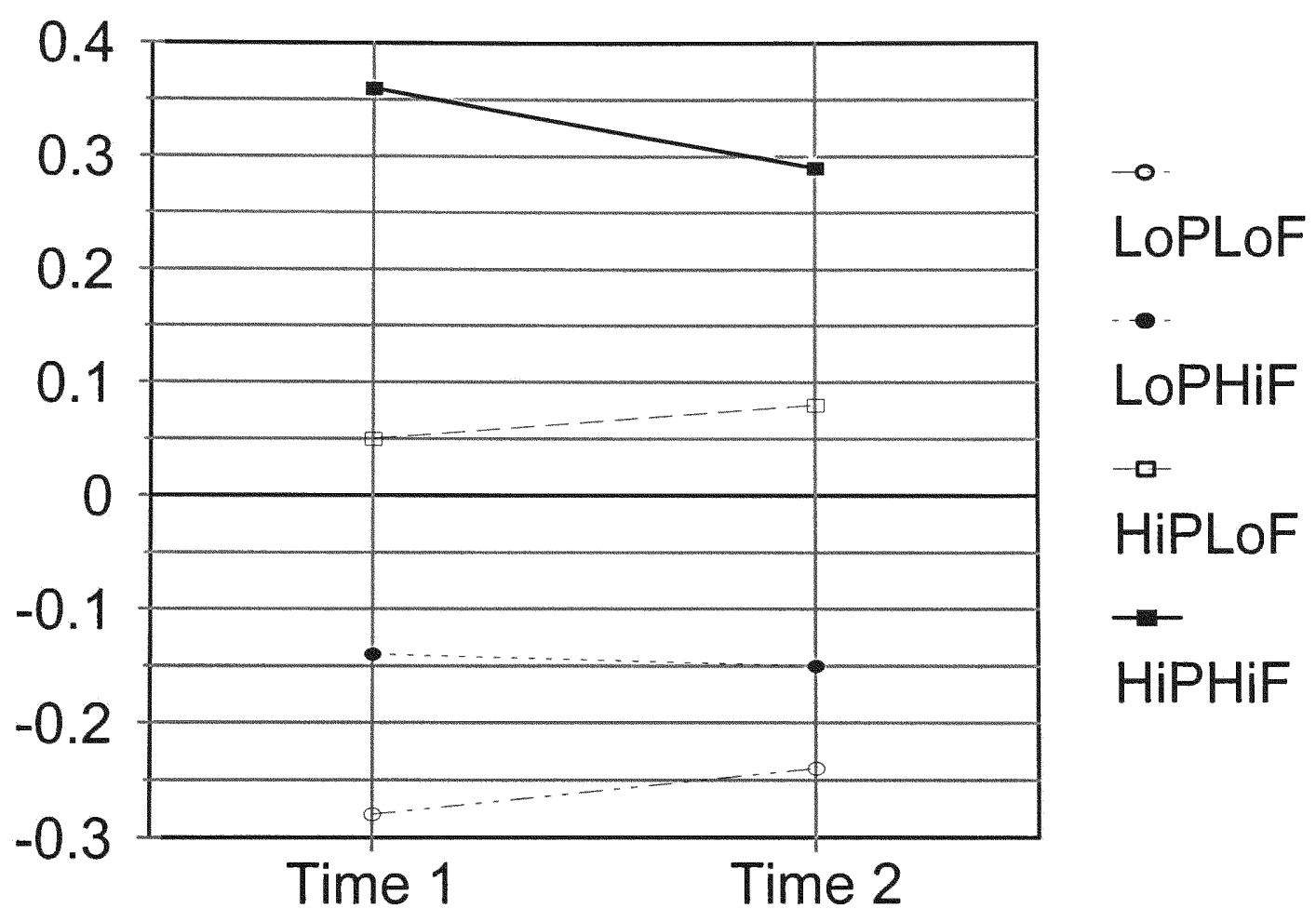


Figure 3.

\section{Achieve by Support-Low Risk}

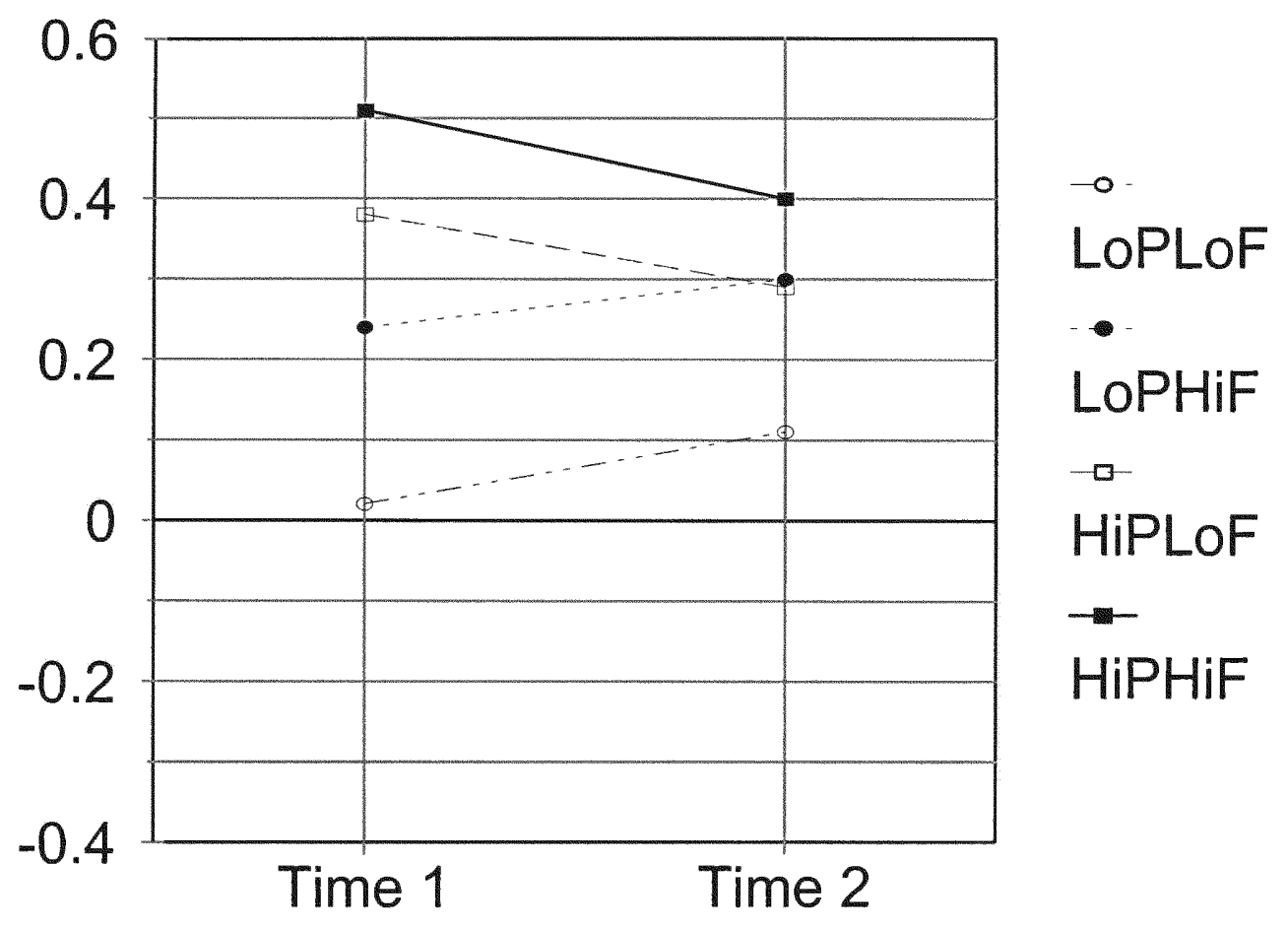


Figure 4.

Achieve by Support- High Risk

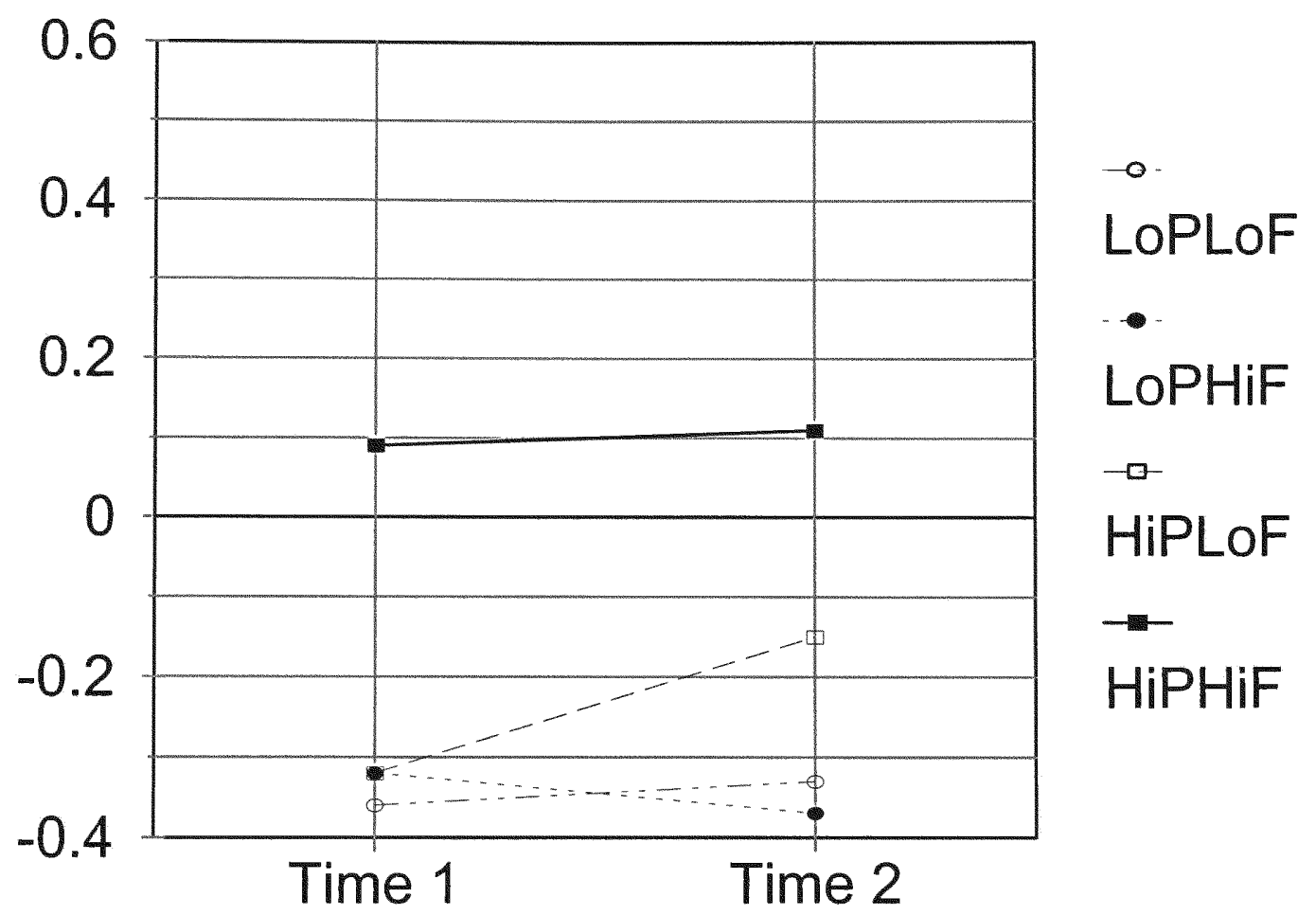




\section{LIST OF REFERENCES}

Achenbach, T.M. \& Edelbrock, C. (1991). Manual for the child behavior checklist and child behavior profile. Burlington, VT: University Associates in Psychiatry.

Agnew, R. (1991). The interactive effects of peer variables on delinquency. Criminology, 29, 47-74.

Ainsworth, M. D. S. (1973). Development of infant-mother attachment. In B. M. Caldwell \& H. Ricciuti (Eds.), Review of child developmental research (Vol. 3, pp. 194). Chicago: University of Chicago Press.

Alexander, K.L., Entwistle, D.R., \& Dauber, S.L. (1993). First-grade classroom behavior: It's short- and long-term consequences for school performance. Child Development, 64, 801-814.

Armsden, G. C., \& Greenberg, M. T. (1987). The inventory of parent and peer attachment: Individual differences and their relationship to psychological well-being in adolescence. Journal of Youth and Adolescence, 16, 427-461.

Ary, D. V., Duncan, T. E., Biglan, A., Metzler, C. W., Noell, J. W., \& Smolkowski, K. (1999). Development of adolescent problem behavior. Journal of Abnormal Child Psychology, 27, 141-150.

Asher, S. R., Hymel, S., \& Renshaw, P. D. (1984). Loneliness in children. Child Development, 55, 1456-1464.

Asher, S. R., \& Dodge, K. A. (1986). Identifying children who are rejected by their peers. Developmental Psychology, 22, 444-449.

Austin, A. M. B., \& Draper, D. C. (1984). The relationship among peer acceptance, social impact, and academic achievement in middle childhood. American Educational Research Journal, 21, 597-604.

Barnes, G. M., \& Farrell, M. P. (1992). Parental support and control as predictors of adolescent drinking, delinquency, and related problem behaviors. Journal of Marriage and the Family, 54, 763-776.

Baumrind, D. (1971). Current patterns of parental authority. Developmental Psychology Monograph, 4, (No. 1, Pt. 2), 1-103.

Berndt, T. J. (1979). Developmental changes in conformity to peers and parents. Developmental Psychology, 15, 608-616. 
Berndt, T. J., \& Perry T. B. (1986). Children's perceptions of friendships as supportive relationships. Developmental Psychology, 22, 640-648.

Berndt, T. J. \& Keefe K. (1995). Friendships' influence on adolescents' adjustment to school. Child Development, 66, 1312-1329.

Bogenschneider, K., Small, S. A., \& Tsay, J. C. (1997). Child, parent, and contextual influences on perceived parenting competence among parents of adolescents. Journal of marriage and the Family, 59, 345-362.

Bogenschneider, K., Wu, M., Raffaelli, M., \& Tsay, J. C. (1998). Parent influences on adolescent peer orientation and substance use: The interface of parenting practices and values. Child Development, 69, 1672-1688.

Booth, C. L., Rubin, K. H., \& Rose-Krasnor, L. (1998). Perceptions of emotional support from mother and friend in middle childhood: Links with social-emotional adaptation and preschool attachment security. Child Development, 69, 427-442. Books.

Bowlby, J. (1969). Attachment and loss. Vol. 1: Attachment. New York: Basic

Brendgen, M., Vitaro, F., \& Bukowski, W. M. (1998). Affiliation with delinquent friends: Contributions of parents, self-esteem, delinquent behavior, and rejection by peers. Journal of Early Adolescence, 18, 244-265.

Brody, G. H., Ge, X., Conger, R., Gibbons, F. X., Murry, V. M., Gerrard, M., \& Simons R. L. (2001). The influence of neighborhood disadvantage, collective socialization, and parenting on African American children's affiliation with deviant peers. Child Development, 72, 1231-1246.

Brown, B. B., Mounts, N., Lamborn S. D., \& Steinberg, L. (1993). Parenting practices and peer group affiliation in adolescence. Child Development, 64, 467-482.

Burks, V. S., \& Parke, R. D. (1996). Parent and child representations of social relationships: Linkages between families and peers. Merrill-Palmer Quarterly, 42, 358378.

Cairns, R. B., Cairns, B. D., Neckerman, H. J., Gest, S. D. \& Gariepy J. -L. (1988). Social networks and aggressive behavior: Peer support or peer rejection. Developmental Psychology, 24, 815-823.

Chassin, L., Presson, C. C., Sherman, S.J., Montello, D., \& McGrew, J. (1986). Changes in peer and parent influence during adolescence: longitudinal versus crosssectional perspectives on smoking initiation. Developmental Psychology, 22, 327-334. 
Conger, R. D., Conger, K. J., Elder, G. H., Jr., Lorenz, F. O., Simons, R. L., \& Whitbeck, L. B. (1992). A family process model of economic hardship and adjustment of early adolescent boys. Child Development, 63, 526-541.

Conger, R. D., Conger, K. J., Elder, G. H., Jr., Lorenz, F. O., Simons, R. L., \& Whitbeck, L. B. (1993). Family economic stress and adjustment of early adolescent girls. Developmental Psychology, 29, 206-219.

Cohen, S., \& Wills, T. A. (1985). Stress, social support, and the buffering hypothesis. Psychological Bulletin, 98, 310-357.

Coley, R. L., \& Hoffman, L. W. (1996). Relations of parental supervision and monitoring to children's functioning in various contexts: Moderating effects of families and neighborhoods. Journal of Applied Developmental Psychology, 17, 51-68.

Cooper, C. R., \& Cooper, R. G., Jr. (1992). Links between adolescents' relationships with their parents and peers: Models, evidence, and mechanisms. In R. D. Parke \& G.W. Ladd (Eds.), Family-peer relationships: Modes of linkage (pp. 135-158). Hillsdale, NJ: Erlbaum.

Crouter, A. C., Helms-Erikson, H., Updegraff, K., \& McHale S. M. (1999). Conditions underlying parents' knowledge about children's daily lives in middle childhood: Between- and within-family comparisons. Child Development, 70, 246-259.

Darling, N., \& Steinberg, L. (1993). Parenting style as context: An integrative model. Psychological Bulletin, 113, 487-496.

De Haan, L. G., \& MacDermid, S. (1998). The relationship of individual and family factors to the psychological well-being of junior high school students living in urban poverty. Adolescence, 33, 73-89.

DeRosier, M. E., Kupersmidt, J. B., \& Patterson, C. J. (1994). Children's academic and behavioral adjustment as a function of the chronicity and proximity of peer rejection. Child Development, 65, 1799-1813.

Dishion, T. J., Patterson, G. R., Stoolmiller, M., \& Skinner, M. L. (1991). Family, school, and behavioral antecedents to early adolescent involvement with antisocial peers. Developmental Psychology, 27, 172-180.

Dishion, T. J., Andrews, D. W., \& Crosby, L. (1995). Antisocial boys and their friends in early adolescence: Relationship characteristics, quality, and interactional process. Child Development, 66, 139-151. 
Dornbusch, S. M., Ritter, P. L., Leiderman, P. H., Roberts, D. F., \& Fraleigh, M. J. (1987). The relation of parenting style to adolescent school performance. Child Development, 58, 1244-1257.

Easterbrooks, M. A., \& Lamb, M. E. (1979). The relationship between quality of infant-mother attachment and infant competence in initial encounters with peers. Child Development, 50, 380-387.

East, P. L., \& Rook, K. S. (1992). Compensatory patterns of support among children's peer relationships: A test using school friends, nonschool friends, and siblings. Developmental Psychology, 28, 163-172.

Eccles, J. S., Buchanan, C. M., Flanagan, C., Fuligni, A., Midgley, C., \& Yee, D. (1991). Control versus autonomy during early adolescence. Journal of Social Issues, 47, $53-68$.

Edelbrock, C., \& Achenbach, T.M. (1984). The teacher version of the Child Behavior Profile: I. Boys aged 6 to 11. Journal of Consulting and Clinical Psychology, 52, 207-217.

Flannery, D. J., Williams, L.L., \& Vazsonyi, A. T. (1999). Who are they and what are they doing? Delinquent behavior, substance use, and early adolescents' after-school time. American Journal of Orthopsychiatry, 69, 247-253.

Franco, N., \& Levitt, M. J. (1997). The social ecology of early childhood: Preschool social support networks and social acceptance. Social Development, 6, 292306.

Franco, N., \& Levitt, M. J. (1998). The social ecology of middle childhood: Family support, friendship quality, and self-esteem. Family Relations: Interdisciplinary Journal of Applied Family Studies, 47, 315-321.

Fuligni, A. J., \& Eccles, J. S. (1993). Perceived parent-child relationships and early adolescents' orientation towards peers. Developmental Psychology, 29, 622-632.

Furman, W., \& Buhrmester, D. (1985). Children's perceptions of the personal relationships in their social networks. Developmental Psychology, 21, 1016-1024.

Gauze, C., Bukowski, W. M., Aquan-Assee, J., \& Sippola, L. K. (1996). Interactions between family environment and friendship and associations with selfperceived well-being during early adolescence. Child Development, 67, 2201-2216.

Glasgow, K. L., Dornbusch, S. M., Troyer, L., Steinberg, L., \& Ritter, P. L. (1997). Parenting styles, adolescents' attributions, and educational outcomes in nine heterogeneous high schools. Child Development, 68, 507-529. 
Gonzales, N. A., Cauce, A. M., Friedman, R. J., \& Mason, C. A. (1996). Family, peer, and neighborhood influences on academic achievement among African-American adolescents: One-year prospective effects. American Journal of Community Psychology, 24, 365-387.

Greenberg, M. T., Siegel, J. M., \& Leitch, C. J. (1983). The nature and importance of attachment relations to parents and peers during adolescence. Journal of Youth and Adolescence, 12, 373-388.

Harter, S. (1985). Manual for the self-perception profile for children. Denver, CO: University of Denver.

Hartup, W. W. (1996). The company they keep: Friendships and their developmental significance. Child Development, 67, 1-13.

Hirsch, B. J., \& Rapkin, B. D. (1987). The transition to junior high school: A longitudinal study of self-esteem, psychological symptomatology, school life, and social support. Child Development, 58, 1235-1243.

Hoffman, M. A., Ushpiz, V., \& Levy-Shiff, R. (1988). Social support and selfesteem in adolescence. Journal of Youth and Adolescence, 17, 307-316.

Hymel, S., Rubin, K. H., Rowden, L., \& LeMare, L. (1990). Children's peer relationships: Longitudinal prediction of internalizing and externalizing problems from middle to late childhood. Child Development, 61, 2004-2021.

Johnson, J.H. (1986). Life events as stressors in childhood and adolescence. Beverly Hills, CA: Sage

Kahn, R. L., \& Antonucci, T. C. (1980). Convoy over the life course: Attachment, roles, and social support. In P. B. Baltes \& O. G. Brim, Jr., (Eds.), Life-span development and behavior (Vol. 3 pp. 253-286). New York: Academic Press.

Komproe, I. H., Rijken, M., Ros, W. J. G., Winnubst, J. A. M., \& Hart, H. (1997). Available support and received support: Different effects under stressful circumstances. Journal of Social and Personal Relationships, 14, 59-77.

Ladd, G. W. (1983). Social Networks of popular, average, and rejected children in school settings. Merrill-Palmer Quarterly, 29, 283-307.

Ladd, G. W., \& Price, J. M. (1987). Predicting children's social and school adjustment following the transition from preschool to kindergarten. Child Development, $58,1168-1189$. 
Ladd, G. W., Profilet, S. M., \& Hart, C. H. (1992). Parents' management of children's peer relations: Facilitating and supervising children's activities in the peer culture. In R. D. Parke \& G. W. Ladd (Eds.), Family-peer relationships: Modes of linkage. Hillsdale, NJ: Lawrence Erlbaum Associates.

Lempers, J. D., Clark-Lempers, D., \& Simons, R. L. (1989). Economic hardship, parenting, and distress in adolescence. Child Development, 60, 25-39.

Leung, K., Lau, S., \& Lam, W. -L. (1998). Parenting styles and academic achievement: A cross-cultural study. Merrill-Palmer Quarterly, 44, 157-172.

Levitt, M. J., Guacci-Franco, N., \& Levitt, J. L. (1994). Social support and achievement in childhood and early adolescence: A multicultural study. Journal of Applied Developmental Psychology, 15, 207-222.

Levitt, M. J., Guacci-Franco, N., \& Levitt, J. L. (1993). Convoys of social support in childhood and early adolescence: Structure and function. Developmental Psychology, $29,811-818$.

Lieberman, M., Doyle, A., \& Markiewicz, D. (1999). Developmental patterns in security of attachment to mother and father in late childhood and early adolescence: Associations with peers relations. Child Development, 70, 202-213.

Lollis, S. P., Ross, H. S., \& Tate, E. (1992). Parents' regulation of children's peer interactions: Direct influences. In R. D. Parke \& G. W. Ladd (Eds.), Family-peer relationships: Modes of linkage. Hillsdale, NJ: Lawrence Erlbaum Associates.

Mason, C. A., Cauce, A. M., Gonzales, N., \& Hiraga, Y. (1996). Neither too sweet nor too sour: Problem peers, maternal control, and problem behavior in African American adolescents. Child Development, 67, 2115-2130.

Mayhew, K. P., \& Lempers, J. D. (1998). The relation among financial strain, parenting, parent self-esteem, and adolescent self-esteem. Journal of Early Adolescence, $18,145-172$.

McFarlane, A. H., Bellissimo, A., \& Norman, G. R. (1995). The role of family and peers in social self-efficacy: Links to depression in adolescence. American Journal of Orthopsychiatry, 65, 402-412.

McLoyd, V. C. (1990). The impact of Economic hardship on black families and children: Psychological distress, parenting, and socioemotional development. Child Development, 61, 311-346.

Mickelson, R. A. (1990). The attitude-achievement paradox among black adolescents. Sociology of Education, 63, 44-61. 
Newcomb, A. F., \& Bagwell, C. L. (1995). Children's friendship relations: A meta-analytic review. Psychological Bulletin, 117, 306-347.

Okagaki, L., \& Sternberg, R. J. (1993). Parental beliefs and children's school performance. Child Development, 64, 36-56.

Okagaki, L., \& Frensch, P. A. (1998). Parenting and children's school achievement: A multiethnic perspective. American Educational Research Journal, 35, 123-144.

Parker, J. F., \& Asher, S. R. (1993). Friendship and friendship quality in middle childhood: Links with peer group acceptance and feelings of loneliness and social dissatisfaction. Developmental Psychology, 29, 611-621.

Patterson, G. R., \& Dishion, T. J. (1985). Contributions of families and peers to delinquency. Criminology, 23, 63-81.

Patterson, C., Cohn, D., \& Kao, B. (1989). Maternal warmth as a protective factor against risks associated with peer rejection among children. Development and Psychopathology, 1, 21-38.

Pettit, G. S., Bates, J. E., \& Dodge, K. A. (1997). Supportive parenting, ecological context, and children's adjustment: A seven-year longitudinal study. Child Development, $68,908-923$.

Pettit, G. S., Bates, J. E., Dodge, K. A., \& Meece, D.W. (1999). The impact of after-school peer contact on early adolescent externalizing problems is moderated by parental monitoring, perceived neighborhood safety, and prior adjustment. Child Development, 70, 768-778.

Reid, M., Landesman, S., Treder, R., \& Jaccard, J. (1989). "My family and friends": Six- to twelve-year-old children's perceptions of social support. Child Development, 60, 896-910.

Russell, A., Pettit, G. S., \& Mize, J. (1998). Horizontal qualities in parent-child relationships: parallels with and possible consequences for children's peer relationships. Developmental Review, 18, 313-352.

Rutter, M. (1979). Protective factors in children's responses to stress and disadvantage. In M.W. Kent \& J.E. Rolf (Eds.), Primary Prevention of Psychopathology, 3. Social competence in children. Hanover, NH: University Press of New England.

Seginer, R. (1983). Parent's educational expectations and children's academic achievements: A literature review. Merrill-Palmer Quarterly, 29, 1-23. 
Shumow, L., Vandell, D. L., \& Posner, J. (1999). Risk and resilience in the urban neighborhood: Predictors of academic performance among low-income elementary school children. Merrill-Palmer Quarterly, 45, 309-331.

Smith-Maddox, R. (1999). The social networks and resources of African American eighth graders: Evidence from the National Education Longitudinal Study of 1988. Adolescence, 34, 169-183.

Steinberg, L., Elmen, J. D., Mounts, N. S. (1989). Authoritative parenting, psychosocial maturity, and academic success among adolescents. Child Development, 60 , 1424-1436.

Steinberg, L., Lamborn, S. D., Dornbusch, S. M., \& Darling, N. (1992). Impact of parenting practices on adolescent achievement: Authoritative parenting, school involvement, and encouragement to succeed. Child Development, 63, 1266-1281.

Steinberg, L., Dornbusch, S. M., \& Brown, B. B. (1992). Ethnic differences in adolescent achievement. An ecological perspective. American Psychologist, 47, 723-729.

Stevenson, H. W., Chen, C., \& Uttal, D. H. (1990). Beliefs and achievement: A study of black, white, and Hispanic children. Child Development, 61, 508-523.

Stocker, M. S. (1994). Children's perceptions of relationships with siblings, friends, and mothers: Compensatory processes and links with adjustment. Journal of Child Psychology and Psychiatry, 35, 1447-1459.

Thoits, P. A. (1986). Social support as coping assistance. Journal of Consulting and Clinical Psychology, 54, 416-423.

Urberg, K. A., Degirmencioglu, S. M., Tolson, J. M., \& Halliday-Scher, K. (1995). The structure of adolescent peer networks. Developmental Psychology, 31,_540547.

van Aken, M. A. G., \& Asendorpf, J. B. (1997). Support by parents, classmates, friends and siblings in preadolescence: Covariation and compensation across relationships. Journal of Social and Personal Relationships, 14, 79-93.

van Beest, M. \& Baerveldt, C. (1999). The relationship between adolescents' social support from parents and from peers. Adolescence, 34, 193-201.

Vandell, D. L., \& Hembree, S. E. (1994). Peer social status and friendship: Independent contributors to children's social and academic adjustment. Merrill-Palmer Quarterly, 40, 461-477. 
Vernberg, E. M. (1990). Psychological adjustment and experiences with peers during early adolescence: Reciprocal, incidental, or unidirectional relationships? Journal of Abnormal Child Psychology, 18, 187-198.

Vitaro, F., Tremblay, R. E., Kerr, M., Pagani, L., \& Bukowski W. M. (1997). Disruptiveness, friends' characteristics, and delinquency in early adolescence: A test of two competing models' of development. Child Development, 68, 676-689.

Warr, M. (1993). Parents, peers, and delinquency. Social Forces, 72, 247-264.

Warr, M. (1993). Age, peers, and delinquency. Criminology, 31, 17-42.

Wentzel, K. R. (1991). Relations between social competence and academic achievement in early adolescence. Child Development, 62,_1066-1078.

Wentzel, K. R., \& Caldwell, K. (1997). Friendships, peer acceptance, and group membership: Relations to academic achievement in middle school. Child Development, 68,_1198-1209.

Wentzel, K. R. (1998). Parent's aspirations for children's educational attainments: Relations to parental beliefs and social address variables. Merrill-Palmer Quarterly, 44, 20-37.

Wenz-Gross, M., Siperstein, G. N., Untch, A. S., \& Widaman, K. F. (1997). Stress, social support, and adjustment of adolescents in middle school. Journal of Early Adolescence, 17, 129-51.

White, K. R., (1982). The relation between socioeconomic status and academic achievement. Psychological Bulletin, 91, 461-481. 


\section{APPENDIX A}

1.) Circle Picture

2.) Support Functions

3.) Self-concept Scale

4.) Loneliness Scale

5.) Depression Scale

6.) Internalizing (CBCL) Scale

7.) School Adaptation Scale

8.) Ecological Risk Scale

9.) Neighborhood Scale 
ID NO.

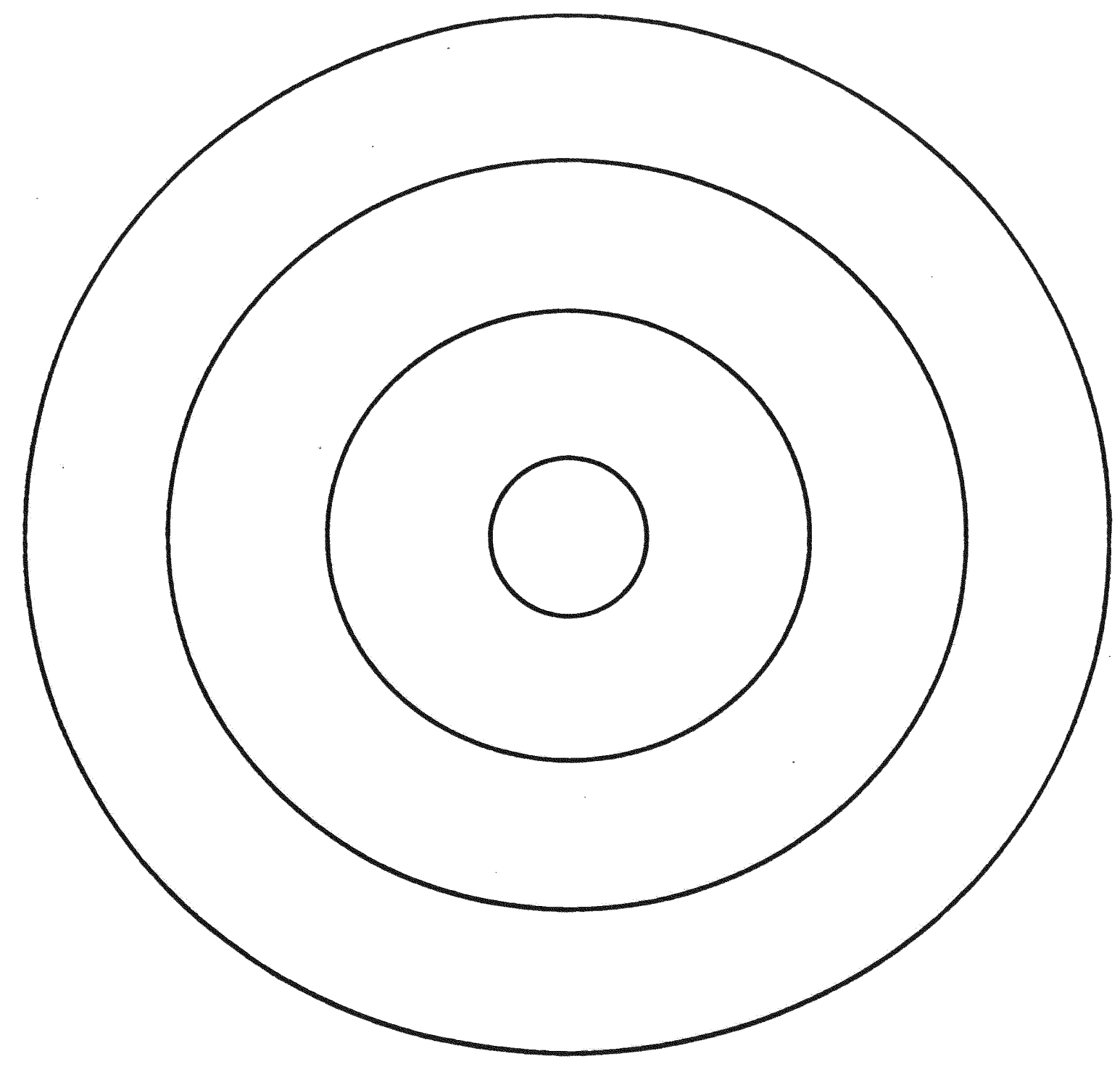


A. (SHOW CIRCLE TO RESPONDENT) We want to put in this circle picture all of the people who are close and important in your life-- the people you really love or like and who really love or like you. First, let's write your name in the middle. (WRITE FIRST NAME IN CENTER). Now, let me tell you how we are going to use these circles, and then we'll start.

(POINT) This first circle is for the people who are the most close and important to you-People you love the most and who love you the most.

(POINT) This middle circle is for people who are not quite as close, but who are still important--people you really love or like, but not quite as much as the people in the first circle.

(POINT) This last circle is for people who are not as close as the others, but who are still important--people you still really love or like, but not quite as much as the people in the middle circle.

(POINT) So, this circle is for the people you love the most, this circle is for people you really love or like, but not quite as much as the first ones, and this one is for people you still really love or like, but not quite as much as the middle ones.

(POINT TO EXAMPLES IN RESPONDENT BOOK) Circles can be empty, full, or in between. You don't need to put everyone you know in the circles-- just the people you love or like very much, and people who love or like you very much.

A1. OK, let's do the first circle. Tell me who is the most close and important to you--who you love the most and who loves you the most. I'll write the person's name in the circle. (INTERVIEWER--GET NAMES OF ALL EXCEPT MOTHER OR FATHER. NUMBER EACH NAME AS IT IS PUT IN, AND PUT IN CLOCKWISE BEGINNING AT TOP OF DIAGRAM).

Is there anyone else you want to put in the first circle?
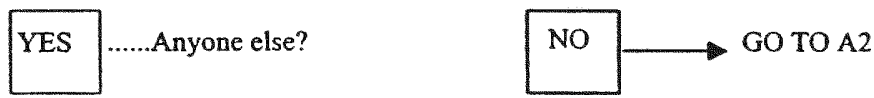

A2. OK, now for the middle circle. Tell me the names of the people who are not quite as close but who are still important--people you really love or like, but not quite as much as the people in the first circle.

Is there anyone else you want to put in the middle circle?
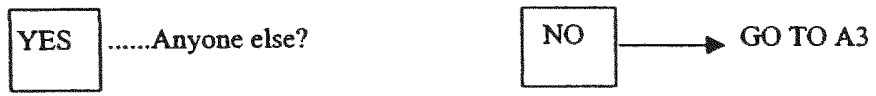

A3. OK, now for the last circle. Tell me the names of the people who are not as close as the others, but who are still important-- people you really love or like, but not quite as much as the people in the middle circle.

Is there anyone else you want to put in the last circle?
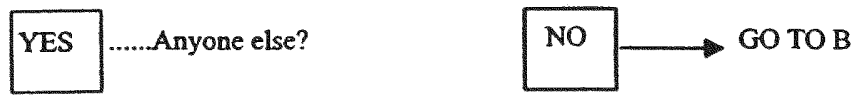
B. Now, I'd like to ask some questions about the people in your circles.

B1. Are there people you talk to about things that are really important to you? Tell me the number in the circle picture of each person you talk to about things that are really important to you.

$$
\begin{array}{lllllllllllllllllllll}
0 & 1 & 2 & 3 & 4 & 5 & 6 & 7 & 8 & 9 & 10 & 11 & 12 & 13 & 14 & 15 & 16 & 17 & 18 & 19 & 20
\end{array}
$$

Other

B2. Are there people who make you feel better when something bothers you or you are not sure about something? Tell me the number of each person who makes you feel better when something bothers you or you are not sure about something.

$\begin{array}{lllllllllllllllllllll}0 & 1 & 2 & 3 & 4 & 5 & 6 & 7 & 8 & 9 & 10 & 11 & 12 & 13 & 14 & 15 & 16 & 17 & 18 & 19 & 20\end{array}$

Other

B3. Are there people who would take care of you if you were sick?

$\begin{array}{lllllllllllllllllllll}0 & 1 & 2 & 3 & 4 & 5 & 6 & 7 & 8 & 9 & 10 & 11 & 12 & 13 & 14 & 15 & 16 & 17 & 18 & 19 & 20\end{array}$

Other

B4. Are there people who like to be with you and do fun things with you?

$\begin{array}{lllllllllllllllllllll}0 & 1 & 2 & 3 & 4 & 5 & 6 & 7 & 8 & 9 & 10 & 11 & 12 & 13 & 14 & 15 & 16 & 17 & 18 & 19 & 20\end{array}$

Other

B5. Are there people who help you with homework or other work you do for school?

$$
\begin{array}{lllllllllllllllllllll}
0 & 1 & 2 & 3 & 4 & 5 & 6 & 7 & 8 & 9 & 10 & 11 & 12 & 13 & 14 & 15 & 16 & 17 & 18 & 19 & 20
\end{array}
$$

Other

B6. Are there people who make you feel special or good about yourself?

$$
\begin{array}{lllllllllllllllllllll}
0 & 1 & 2 & 3 & 4 & 5 & 6 & 7 & 8 & 9 & 10 & 11 & 12 & 13 & 14 & 15 & 16 & 17 & 18 & 19 & 20
\end{array}
$$

Other 
ID NO.

WHAT I AM LIKE

REALLY SORT OF
TRUE TRUE
for me for me
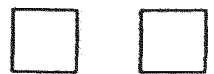

Some kids would

rather play outdoors

in their spare time
SORT OF REALLY

TRUE TRUE

for me for me

BUT

Other kids would rather watch T. V.

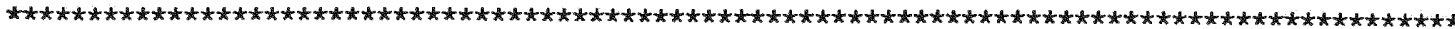

J1.
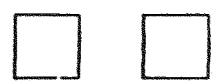

Some kids feel that

they are very good at

their school work

J2.
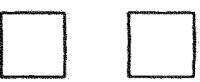

Some kids find it

hard to make friends

J3.
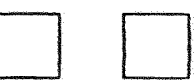

Some kids are often

unhappy with themselves

BUT

BUT

Other kids find it's

pretty easy to make

friends
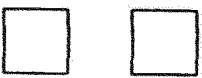

whether school work assigned to them

34.

Some kids feel they

are just as smart as

other kids their age

BUT

Other kids aren't so sure and wonder if they are as smart
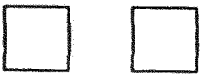

35.

Some kids have alot of friends

BUT

other kids don't have very many friends
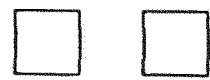

56.

Some kids don't like

the way they are

leading their life

BUT

other kids do like the way they are leading their 1 ife
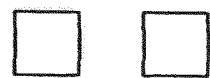

Some kids are pretty

slow in finishing

their school work

38.

Some kids would like to have alot wore friends
BUT
BUT

Other kids have as many friends as they want
Other kids can do their school work quickly
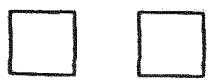

PLEASE TURN OVER AND DO THE OTHER SIDE 
REALLY SORT OF
TRUE TRUE
for me for be

J9.
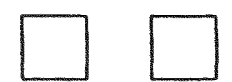

Some kids are happy

with themselves as

a person

$\mathrm{J} 10$.
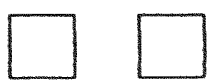

Some kids often forget

what they learn

BUT

J11.
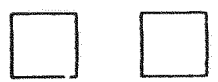

Some kids are lways doing things with

alot of kids

$\mathrm{J} 12$.
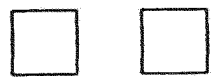

Some kids like the

kind of person they

are

J13.
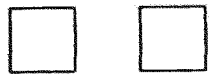

Some kids do very well

at their classwork

$\mathrm{J} 14$
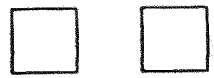

Some kids wish that more people their age

liked them

J15.

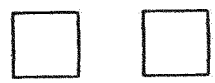

Some kids are very

happy being the way

they are

J16.
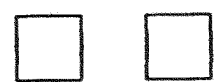

Some kids have trouble

figuring out the

answers in school

$\mathrm{J17.}$
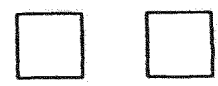

Some kids are popular with others their age

J18.

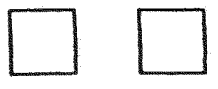

Some kids aren't very

happy ith the way they

do alot of things

BUT

BUT
SORT OF REALLY

TRUE TRUE

for me for me

other kids are often not happy with themselves
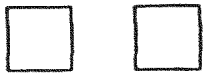

other kids can remember things easily

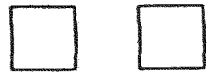

other kids usually do

things by themselves
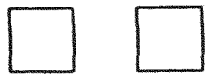

BUT

other kids often wish

they were someone else
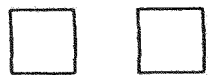

BUT

other kids don't do very

well at their classwork
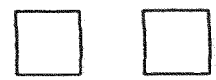

BUT

Others kids feel that most people their age do like them
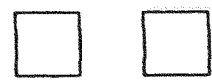

BUT

other kids wish they

were different
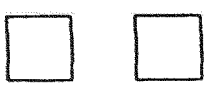

BUT

Other kids almost always can figure out the answers

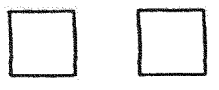

BUT

other kids are not very popular
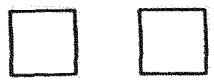

BUT

other kids think the way they do things is fine
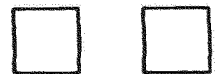
ID No.

HOW I FEEL AT SCHOOL

a. I like roller skating.

1

2

That's always
true about me

That's true about
me most of the
time

3

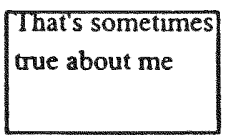

4

5

That's hardly
ever true about
me

That's not true
about me at all

\section{I like to read.}

That's always
true about me

That's true about
me most of the
time

That's sometimes
true about me

That's hardly
ever true about
me

2. I like school.

That's always
true about me

That's true about
me most of the
time

That's sometimes
true about me

That's bardly
ever true about
me

\section{I feel alone at school.}

That's always
true about me

That's true about
me most of the
time

That's sometimes
true about me

That's hardly ever true about me
That's not true about me at all

\section{I can find a friend in my class when I need one.}

That's always
true about me

That's true about
me most of the
time

That's sometimes
true about me
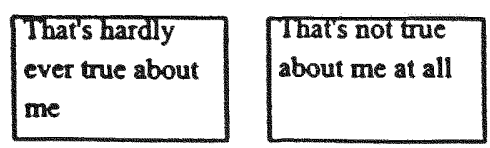

PLEASE TURN OVER AND DO THE OTHER SIDE 


\section{Il like science.}

That's always
true about me

That's true about
me most of the
time
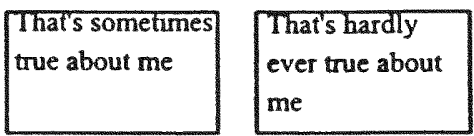

That's not true

about me at all

6. I get along with my classmates.

That's always
true about me

That's true about
me most of the
time

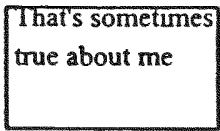
That's hardly
ever true about
me

about me at all

7. I feel left out of things at school.

That's always
true about me

That's true about
me most of the
time

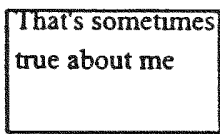
That's hardly ever true about me

8. There are other kids I can go to when I need help in school.

Thar's always
true about me

Ihat's true about
me most of the
time
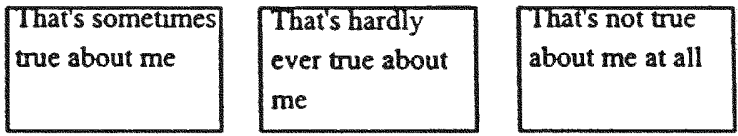

\section{I like to paint and draw.}

That's always
true about me

That's true about
me most of the
time

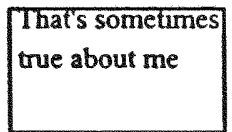
That's hardly
ever true about
me

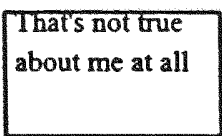

\section{I'm lonely at school.}

That's always
true about me

That's true about
me most of the
ime

Thats sometimes
true about me

That's hardly
ever true about
me

That's not true
about me at all


Example:

I read books all the time.

1 read books once in a while.

I never read books.

Jem I

I am sad once in a while.

I am sad many times.

I am sad all the time.
Jiem 6

Things bother me all the time.

Things bother me many times.

Things bother me once in a while.

trem $^{-}$

Hem: 2

Nothing will ever work out for me.

$\square$ I am not sure if things will work out for me.

$\square$ Things will work out for me O.K. hem :

$\square$ I do most things O.K.

$\square$ I do many things wrong.

$\square$ I do everything wrong. Jem 4

$\square$ I hate myself.

$\square$ I do not like myself.

$\square$ I like myself. Item 5

I feel like crying everyday.

I feel like crying many days.

I feel like crying once in awhile.
I look O.K.

There are some bad things about my looks.

I look ugly.

Jtem:

I do not feel alone.

I feel alone many times.

I feel alone all the time.

nem 9

$\square$ I have plenty of friends.

$\square$ I have some friends but I wish I had more.

$\square$ I do not have any friends. Irem 10

Nobody really loves me.

$\square$ I am not sure if anybody loves me.

$\square$ I am sure that somebody loves me. 
Below is a list of items that describe pupils. For each item that describes the pupil now or within the past 2 months, please circle the 2 if the item is very true or often true of the pupil. Circle the 1 if the item is somewhat or sometimes true of the pupil. If the item is not true of the pupil, circle the 0 . Please answer all items as well as you can, even if some do not seem to apply to this pupil.

\section{$0=$ Not True (as far as you know) $\quad 1=$ Somewhat or Sometimes True $\quad 2=$ Very True or Often True}

\begin{tabular}{|c|c|c|c|}
\hline 0 & 1 & 2 & 1. Acts too young for his/her age \\
\hline 0 & 1 & 2 & 2. Hums or makes other odd noises in class \\
\hline 0 & 1 & 2 & 3. Argues a lot \\
\hline 0 & 1 & 2 & 4. Fails to finish things he/she stans \\
\hline 0 & 1 & 2 & 5. Behaves like opposite sex \\
\hline 0 & 1 & 2 & 6. Defiant. talks back to staff \\
\hline 0 & 1 & 2 & 7. Bragging, boasting \\
\hline 0 & 1 & 2 & 8. Can't concentrate, can't pay attention for long \\
\hline 0 & 1 & 2. & $\begin{array}{l}\text { 9. Can't get his/her mind off certain thoughts: } \\
\text { obsessions (describe): }\end{array}$ \\
\hline
\end{tabular}

- 12 10. Canit sit still. restless, or hyperactive

$0 \quad 1211$. Clings to adults or 100 dependent

01212 Complains of loneliness

- 12 13. Confused or seems to be in a 109

01214. Cries a lot

0 12 15. Fidgets

01216 . Cruelty, bullying, or meanness to others

- 12 17. Daydreams or gets lost in hisher thoughts

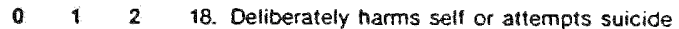

- 12 19. Demands a lot of attention

012 20. Destroys his/her own things

- 1221 . Destroys property belonging to others

$\begin{array}{llll}0 & 1 & 22 & 22 . \\ & \text { Difficulty following directions }\end{array}$

$\begin{array}{lll}0 & 1 & 23 . \\ 0 & 1 & 2\end{array}$

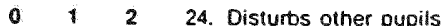

- 12 25. Doesn't get along with other pupils

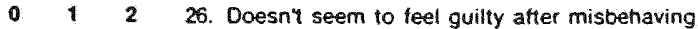

$\begin{array}{lll}1 & 2 & 27 . \\ 0 & 1 & \end{array}$

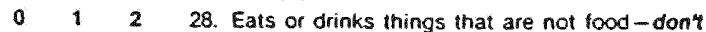
include sweets describe)

- 12 29. Fears certain animals, situations, or places other than school (describe):

- 1230 . Fears going to school
31. Fears helshe might think or do something bad

32. Feels hershe has to be perfect

33. Feels or complains that no one loves him/her

34. Feels others are out to get him/her

35. Feels worthless or inferio

36. Gets hurt a lot, accident-prone

37. Gets in many fights

38. Gets teased a lot

39. Hangs around with others who get in trouble

40. Hears sounds or voices that aren't there ldescriber:

41. Impulsive or acts withoul thinking

42. Would rather be alone than with others

43. Lying or cheating

44. Bites fingernails

45. Nervous, high-strung, or tense

46. Nervous movements or iwitching (describe):
- 12 48. Not liked by other pupils
$\begin{array}{llll}0 & 1 & 2 & 49 . \\ & \text { Has difficulty learning }\end{array}$
- 1250 . Too fearful or anxious
$\begin{array}{lll}0 & 2 & 21 . \\ 0 & 1 . & \text { Feels dizzy }\end{array}$
0 1. 2 52. Feets too guilty
$\begin{array}{llll}0 & 1 & 2 & 53 . \\ 0 & 1 & \text { Talks out of tum }\end{array}$
- 1254 . Overtired
- 12 55. Ovenweight
56. Physical probtems without known medical cause:
a. Aches or pains (not stomach or headaches)
b. Headaches
c. Nausea, leel sick
d. Problems with eyes (not if corrected by glasses) (describe):

01247 . Overconforms to rules

e. Rashes or other skin problems

f. Stomachaches or cramps

g. Vomiting, throwing ip

h. Other (describe): 


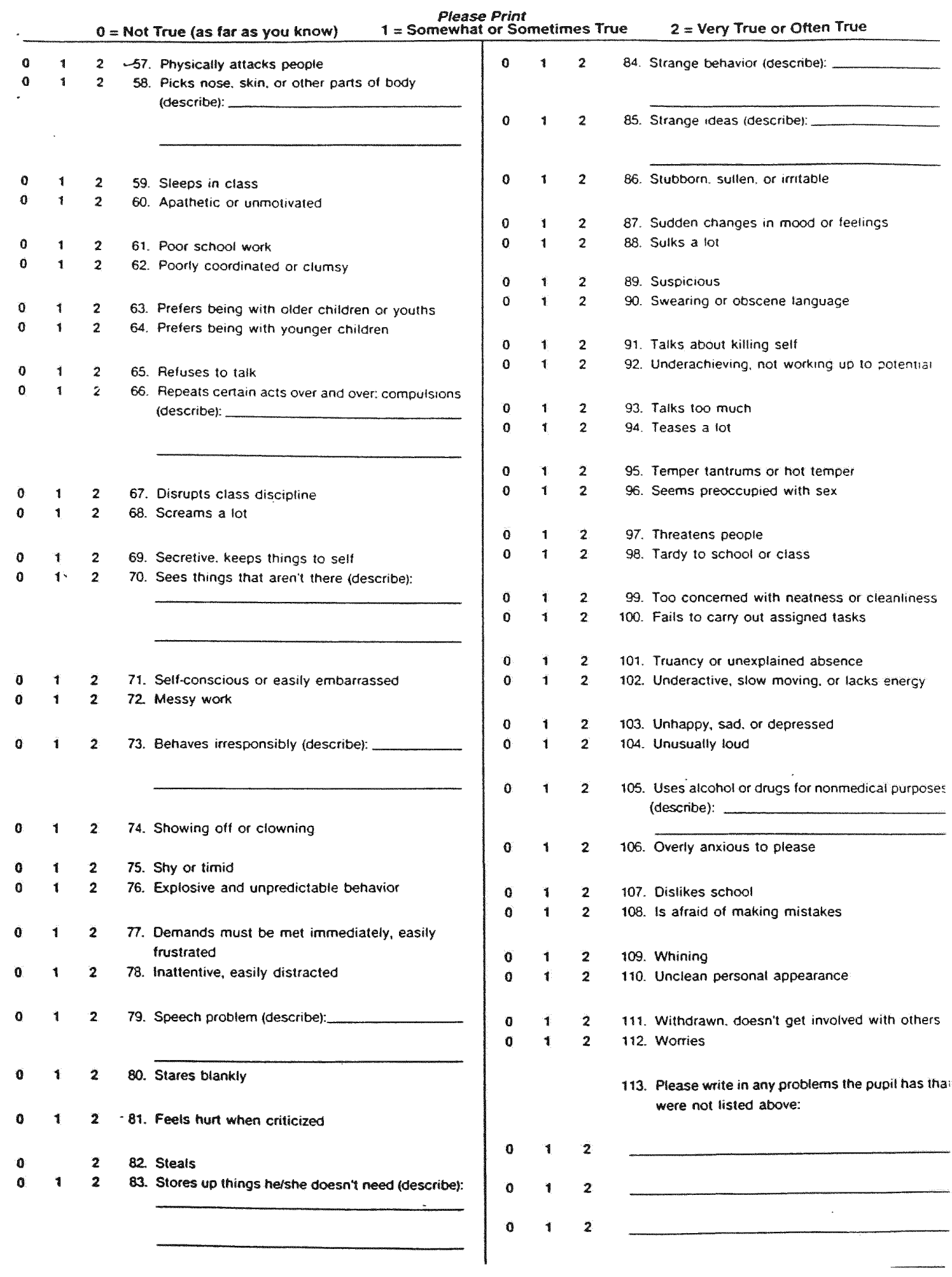




\section{SCHOOL ADAPTATION SCALE}

10 No.

Please circle one number for each item below.

= Exactly like this child

$4=$ Somewhat like this child
$2=$ Very much like this child

$5=$ A little like this child
$3=$ Pretty much like this child

$6=$ Not at all like this child

A1. Very enthusiastic, interested in a lot of different things,

$\begin{array}{ll}\text { Exactly } & \text { Not at } \\ \text { Like } & \text { All Like }\end{array}$ likes to express his or her ideas

All Like

A2. Rather high strung, tense, and nervous

$\begin{array}{llllll}1 & 2 & 3 & 4 & 5 & 6\end{array}$

A3. Fights too much; teases, picks on or bullies other children

1

A4. Usually in a happy mood; very cheerful 1

A5. Doesn't concentrate, doesn't pay attention for long 12

A6. Is polite, helpful, considerate of others 12

A7. Very timid, afraid of new things or new situations 1

A8. Is awfully restless, fidgets all the time, can't sit still

123

A9. Tells lies or fibs 123 123

A10. Is creative or imaginative 1

.11. Has a very strong temper; loses it easily 1 23

A12. Keeps to himself or herself; spends a lot of time alone 2

A13. Acts too young for his or her age, cries a lot or has tantrums 1 2

A14. Is disobedient at school 1

$\begin{array}{lllll}2 & 3 & 4 & 5 & 6\end{array}$

CHILO BEHAVIOR CHECKLIST: TEACHER'S REPORT FORM FOR AGES 5-18
The following material is copyrighted (1991) by Thomas $M$. Achenbach. Center for Children, Youth, \& Families, $U$. of
Vermont, 1 South Prospect St., Burtington, VT o5401. Permission is required. Unauthorized use is strictly prohibited.

B. How well do you know this student? Not well Moderately Well Very Well

Compared to typical pupils of the same age:

81. How hard is he/she working?

B2. How appropriately is he/she behaving?

33. How much is he/she learning?

84. How happy is he/she? 
1. OK, now I want to ask you about several things that could happen to any family. Tell me which of them have happened to you or your family in the past year.

I1. Do you have a new baby brother or sister in your family?

12. Did anyone in your family die in the past year? (IF YES)... Who died in your family?

13. Did you have to go to the hospital because you were very sick or hurt?

14. Did your Mom and Dad become divorced or separated in the past year?

15. Did you have a very poor report card from school?

16. Did you have any other problems in school? (IF YES)...What problems did you have?

17. Did your Mom or Dad have to go to the hospital because he or she was very sick or hurt?

18. Did your family move?

I 9. Did your family worry about money a lot?

110. Was anyone in your family robbed or attacked?

I11. Did your Mom or Dad lose their job?

112. Did someone in your family get into trouble with the police?

I13. Did you get a new stepmother or stepfather?

114. Did your Mom or Dad stay at home because they couldn't get a job? 
116. Did someone you like very much go away?

117. Do any of your friends belong to gangs?

I18. Have any of your friends been in trouble with the police?

119. Did a close friend die or was a close friend seriously injured in the past year? (IF YES) Could you tell me more about that?

120. Did anything else important happen to you or your family during the past year? (IF YES)...Tell me about it.

[RESPONDENT BOOK]

122. How often does your family have problems paying for things that the family really needs, like food, clothing, or rent--never, very little, sometimes, often, or almost always? You can just tell me the number.

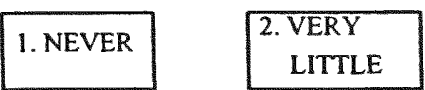

$$
\text { 3. SOMETIMES }
$$$$
\text { 4. OFTEN }
$$$$
\begin{aligned}
& \text { 5. ALMOST } \\
& \text { ALWAYS }
\end{aligned}
$$

\section{J. [GIVE "REMEMBER.... PAST TWO WEEKS" TO R.]}

OK, here are a few more questions that you can answer by yourself. People sometimes have different feelings and ideas. This form lists the feelings and ideas in groups. From each group of three sentences, pick one sentence that describes you best for the past two weeks. After you pick a sentence from the first group, go on to the next group. There is no right answer or wrong answer. Just pick the sentence that best describes the way you have been recently. Put an $\mathrm{X}$ in the box next to the sentence you pick. Remember, pick out the sentences that describe you best in the PAST TWO WEEKS. [WHEN COMPLETE, TAKE BACK AND CHECK. GO TOK.]

\section{K. [GIVE NEIGHBORHOOD SCALE TO R]}

Here is a short group of questions for you to answer. These questions ask you to describe your neighborhood. For each question, put an $\mathrm{X}$ in the space next to the description that is most like your neighborhood.

[WHEN COMPLETE, TAKE BACK AND CHECK. GO TO L.] 


\section{YOUR NEIGHBORHOOD}

K. Below are some groups of words that might be used to describe your neighborhood. For each group, put an X next to the word that best describes your neighborhood.

\section{HOW WOULD YOU DESCRIBE YOUR NEIGHBORHOOD?}

(Put an $\mathrm{X}$ next to ONE word in each group).

1.

\begin{tabular}{l} 
Noisy \\
\hline Quiet \\
In Between
\end{tabular}

3. Full of friends Full of strangers In Between

5.

Dirty
Clean
In Between

7. Pleasant Unpleasant In Between
2. Safe Dangerous In between

4. A place where you want to stay A place you want to leave In between

6. Friendly Unfriendly In between

8. Changing Staying the same In between 
B.S., Biochemistry

College of Staten Island,

Staten Island, New York

1993

Certified Behavior Analyst

(State of Florida)

1996-1999

Research Assistant

Florida International University (North Campus)

Social Network and Achievement Project (SNAP)

Grant obtained from the Spencer Foundation;

Social Transition Project,

Grant obtained from the National Science

Foundation (NSF)

1998

M. A., Behavior Analysis

Florida International University

Miami, Florida

1999 - Present

Team Leader/Support Coordinator, Community of Landmark.

Opa Locka, Florida

\section{PUBLICATIONS AND PRESENTATIONS}

Crooks, N. C. (1993). Guessing Behaviors of Children. Presented at the annual meeting of the Florida Association of Behavior Analysts, (FABA), Ft., Lauderdale, Florida.

Crooks, N. C., Gewirtz, J.L., \& Pelaez, M. (1996). Rule-Following in Children: A Developmental Perspective. Paper presented at the annual meeting of the Association for Behavior Analysis,(ABA), San Francisco, California.

Crooks, N. C. Gewirtz, J.L., \& Pelaez, M. (1996). Contingent Relations Description Facilitates Rule-Following in a Subsequent Generalization Task. Presented at the annual meeting of the Association of Behavior Analysts (ABA), Orlando, Florida. (1998) 
Crooks, N. A., \& Levitt, M. J. (2000, June). The interaction of parent monitoring and support in relation to self concept in early adolescence. Presented at the meeting of the American Psychological Society, Miami.

Levitt, M. J., Levitt, J., Bustos, G. L., Crooks, N. A., Levitt, J. L., Santos, J. D., \& Telan, P. (2002, August). Multiple attachments and well-being in middle childhood and adolescence. To be presented at the meeting of the American Psychological Association, Chicago.

Levitt, M. J., Levitt, J., Bustos, G. L., Crooks, N. A., Levitt, J. L., Santos, J. D., \& Telan, P. (2002, April). Patterns of social support and school sdaptation scross the child to adolescent transition. Presented at the meeting of the American Educational Research Association, New Orleans.

Levitt, M. J., Levitt, J., Bustos, G. L., Crooks, N. A., Levitt, J. L., Santos, J. D., \& Telan, P. (2002, April). Ethnic minority status and school adaptation in the transition to adolescence: The mediating role of ecological risk and social support. Presented at the meeting of the American Educational Research Association, New Orleans.

Levitt, M. J., Levitt, J., Bustos, G. L., Crooks, N. A., Levitt, J. L., Santos, J. D., \& Telan, P. (2001, November). Social networks and achievement: A prospective research program. Presented at the meeting of the Florida Educational Research Association, Marco Island, FL.

Levitt, M. J., Crooks, N. A., Bustos, G. L., Levitt, J. L., Telan, P., Santos, J., Franco, N., Hodgetts, J., Milevsky, A., \& Oliva, M. (2001, April). Ecological risk, social support, and well-being in the transition to adolescence. Presented at the meeting of the Society for Research in Child Development, Minneapolis.

Levitt, M. J., Bustos, G. L., Crooks, N. A., Levitt, J. L., Santos, J. D., \& Telan, P. (2000, June). Personal and situational predictors of social support across the transition to adolescence. Presented at the meeting of the American Psychological Society, Miami.

Levitt, M. J., Crooks, N., Bustos, G. L., Santos, J., Telan, P., Silver, M. E., Branscum, E., \& Levitt, J. L. (1998, August). The social ecology of well-being in middle childhood. Presented at the meeting of the American Psycological Association: Scientific Affairs Focus on Science Session. San Francisco.

Telan, P., Santos, J. D., Levitt, M. J., Bustos, G. L., Crooks, N. A., \& Silver, M. E. (1999, April). Social support, life stress, and depression in an ethnically and economically diverse sample of pre-adolescents. Presented at the meeting of the Society for Research in Child Development, Albuquerque. 